\title{
Recent Advances and Perspectives on Starch Nanocomposites for Packaging Applications
}

\author{
Zainab Waheed Abdullah ${ }^{\mathrm{a}, \mathrm{b}}$ and Yu Dong ${ }^{\mathrm{a}, *}$ \\ ${ }^{a}$ School of Civil and Mechanical Engineering, Curtin University, Perth, WA6845, Australia \\ ${ }^{a, b}$ Technical Engineering College-Baghdad, Middle Technical University, Baghdad, Iraq \\ * Correspondence: Y.Dong@curtin.edu.au; Tel.: +61 892669055 \\ Note: ORCID for Z. W. Abdullah (0000-0002-7920-5345) \\ ORCID for Y. Dong (0000-0003-1774-1553)
}

\begin{abstract}
Starch nanocomposites are popular and abundant materials in packaging sectors. The aim of this work is to review some of the most popular starch nanocomposite systems that have been used nowadays. Due to a wide range of applicable reinforcements, nanocomposite systems are investigated based on nanofiller type such as nanoclays, polysaccharides and carbonaceous nanofillers. Furthermore, the structures of starch and material preparation methods for their nanocomposites are also mentioned in this review. It is clearly presented that mechanical, thermal and barrier properties of plasticised starch can be improved with well dispersed nanofillers in starch nanocomposites.
\end{abstract}

\section{KEYWORDS}

Natural materials, blends, nanocomposites

\section{Introduction}

One of the most serious environmental problems is associated with littered plastic wastes. Around the world, about 150 million tons of plastic wastes are produced every year in a significantly increasing manner [1, 2]. Easy processability, good mechanical, barrier and 
thermal properties in addition to relatively low cost are typical material merits to use synthetic polymers for many applications. The packaging industry has a large portion of such applications particularly for short life usage including bowls, cups, plates and plastic bags (Fig. 1). As such, it becomes a suitable solution to use biodegradable polymers to replace their synthetic counterparts. The major reasons to consider biopolymers as the alternative lie in their resource renewability, availability, biodegradability and ecofriendliness [1, 3-9].

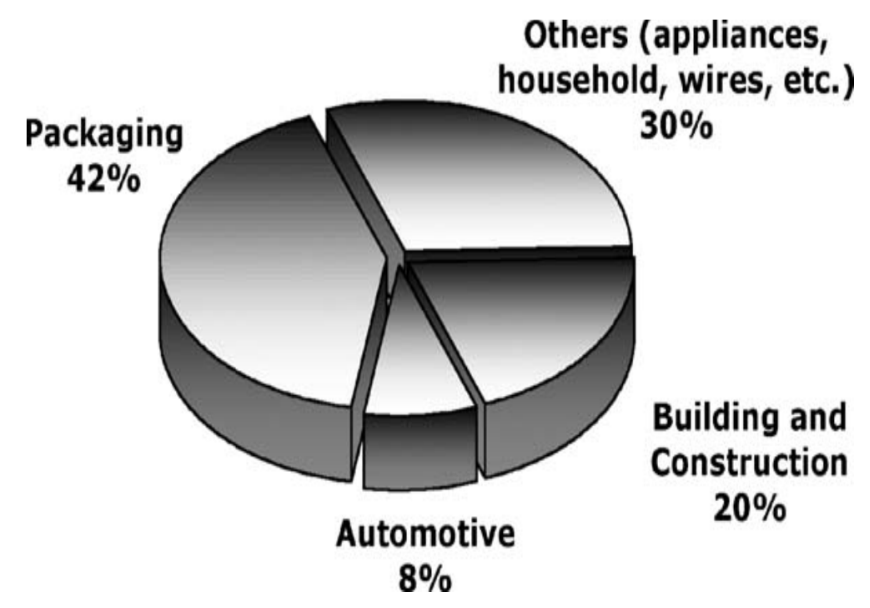

Fig. 1 Industrial applications for polymer use [2]

Starch is a completely biodegradable polymer in soil and compost with natural availability. It is a semicrystalline polymer in presence of transparent, odourless, nontoxic and cost-effective characteristics $[8,10]$. Unfortunately, the difficulty in using starch as a neat polymer arises from the closeness between its melting temperature and degradation temperature. To tackle such a material selection issue, gelatinised, plasticised or thermoplastic starch (TPS) are generally utilised [11]. In the gelatinisation process, heat and pressure are employed to completely destroy crystalline structures of starch for their conversion into amorphous structures with the presence of water and/or plasticisers. In order to produce plasticised starch, the strong hydrogen bonding between starch granules is replaced with the same counterpart between starch and plasticiser molecules [12-14]. Paes et al. [15] evaluated the effect of gelatinisation conditions like temperature and shear rate on mechanical properties of TPS. Two 
different shear rates of 18000 and $150 \mathrm{rpm}$ were used at the temperature levels of $70,80,90$ and $100^{\circ} \mathrm{C}$. The high shear rate reduced mechanical properties of TPS at all temperatures compared with the low shear counterpart due to the phase separation. Talja et al. [16] studied the effect of glycerol, sorbitol, and xylitol as plasticisers on mechanical, thermal and barrier properties of potato starch. Generally, tensile strength, Young's modulus, glass transition temperature $\left(T_{g}\right)$ and water vapour permeability (WVP) decreased with increasing the plasticiser concentration. Nonetheless, glycerol has the higher effect compared with other polyols owing to the phase separation at the high concentration. Whereas, the elongation at break increased linearly with increasing the polyol concentration. Shi et al. [17] used citric acid and glycerol as a co-plasticisers to prepare TPS with higher thermal stability as opposed to TPS plasticised with glycerol only, along with the improvements of compatibility and processability. TPS still has poor mechanical, thermal and barrier properties generally required to be much better for packaging materials. These drawbacks can be overcome by cross-linking, blending with other polymers and/or reinforcing with nanofillers [8, 10, 14]. For instance, Reddy and Yang [18] found that cross-linked starch with citric acid had an increase in tensile strength by $150 \%$ and $20 \%$ reduction in the WVP, respectively, when compared with noncross-linked counterpart. This was followed by the decrease in weight loss by $20 \%$ when films were heated up to $600^{\circ} \mathrm{C}$. According to Sam et al. [9], the most popular polymers blended with starch to eliminate these drawbacks are polyvinyl alcohol (PVA), poly( $\beta$-hydroxyalkanoates) (PHA), polylactide acid (PLA), poly( $\varepsilon$-caprolactone) (PCL), etc.

In this paper, according to most popular nanofillers used, starch nanocomposites reinforced with nanoclays, polysaccharides, and carbonaceous nanofillers are particularly reviewed in the description of preparation methods and property improvements particularly targeting packaging applications. 


\section{Starch sources and structure}

Starch belongs to polysaccharide family having completely renewable and compostable features. Starch is the end product of photosynthesis for chemical storage of energy in leaves, stems, roots, fruits and tubers in form of water-insoluble granules. It is extracted easily because of water-insolubility obtained from barley, rye, potato, wheat, rice, corn, maize, waxy maize, pea, cassava and shoti $[7,12,19-21]$. Furthermore, there are new starch resources like banana, okenia, mango, pineapple and oat [22-24]. According to starch source, it has a variety of granular shapes with the dimensions ranging from $0.5-175 \mu \mathrm{m}$, as presented in Fig. $2[10,12$, $19,20]$.
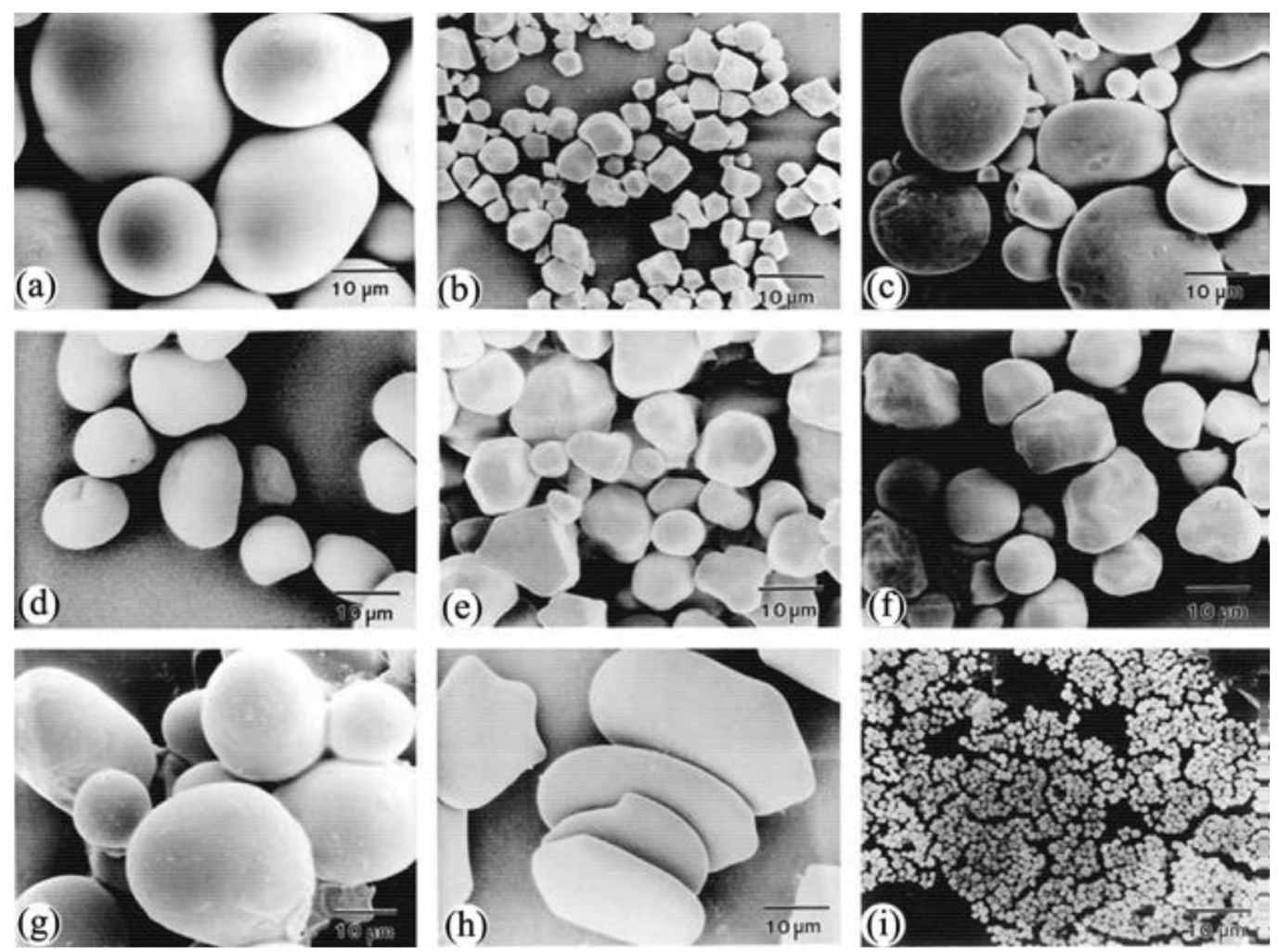

Fig. 2 SEM micrographs of native starch: (a) potato, (b) rice, (c) wheat, (d) mung bean, (e) maize, (f) waxy maize, (g) tapioca, (h) shoti and (i) leaf starch [24]. 
Table 1 Composition and structures of starch from different sources

\begin{tabular}{|c|c|c|c|}
\hline Starch & Amylose $(\%)$ & Amylopectin (\%) & References \\
\hline \multirow[t]{2}{*}{ Maize } & $26-28$ & $71-73$ & [12] \\
\hline & 25 & 75 & [24] \\
\hline \multirow[t]{2}{*}{ Waxy maize } & $<1$ & $>99$ & {$[8,12]$} \\
\hline & 0 & 100 & {$[24]$} \\
\hline \multirow[t]{2}{*}{ Amylomaize } & $48-77$ & $23-52$ & [8] \\
\hline & $50-80$ & $20-50$ & [12] \\
\hline Amylomaize-5 & 53 & 47 & {$[24]$} \\
\hline Corn & $17-25$ & $75-83$ & [8] \\
\hline High-amylose corn & $55-70$ & $30-45$ & {$[8]$} \\
\hline Amylomaize-7 & 70 & 30 & [24] \\
\hline \multirow[t]{3}{*}{ Potato } & $17-24$ & $76-83$ & [8] \\
\hline & $20-25$ & $74-79$ & [12] \\
\hline & 22 & 78 & [24] \\
\hline \multirow[t]{3}{*}{ Wheat } & $20-25$ & $75-80$ & {$[8]$} \\
\hline & $26-27$ & $72-73$ & [12] \\
\hline & 23 & 77 & {$[24]$} \\
\hline \multirow[t]{2}{*}{ Rice } & $15-35$ & $65-85$ & {$[8]$} \\
\hline & 19 & 81 & {$[24]$} \\
\hline Chickpeas & $30-40$ & $60-70$ & {$[8]$} \\
\hline \multirow[t]{2}{*}{ Tapioca (cassava) } & $19-22$ & $28-81$ & [8] \\
\hline & 17 & 83 & [24] \\
\hline \multirow[t]{2}{*}{ Banana } & $17-24$ & $76-83$ & {$[8]$} \\
\hline & 20 & 80 & {$[24]$} \\
\hline Cush-cush Yam & $9-15$ & $85-91$ & {$[8]$} \\
\hline Shoti & 30 & 70 & [24] \\
\hline
\end{tabular}

Starch is a polymeric carbohydrate material consisting of $15-30 \%$ amylose and $70-80 \%$ amylopectin depending on their resources, as summarised in Table 1. Amylose to amylopectin ratio is roughly 1:3 in most starch resources. However, there are other mutant starch resources containing higher amylopectin contents like waxy barley, waxy rice, waxy potato and waxy maize with approximately $100 \%$ amylopectin. In comparison, the high amylose content in 
starch can also be found in amylomaize-5 and amylomaize-7 [24, 25]. Amylose is a linear macromolecular biopolymer in which D-glucose units are bonded by $\alpha(1-4)$ linkage with a molecular weight of $10^{5}-10^{6} \mathrm{~g} \mathrm{~mol}^{-1}$. Amylose molecules have the parallel orientation to each other and tend to form hydrogen bonding between adjacent chains (Fig. 3a). On the other hand, amylopectin is a highly multiple-branched macromolecular biopolymer, bonded by $\alpha(1-4)$ and $\alpha(1-6)$ linkages with the molecular weight of $10^{7}-10^{9} \mathrm{~g} \mathrm{~mol}^{-1}$. Amylopectin chains have the radial arrangement of alternative crystalline and amorphous areas with branched points (Fig. 3b) $[3,13,19,20,26-28]$. Amylopectin molecules can be described by their chain length and degree of polymerisation $[24,25]$.

(a)
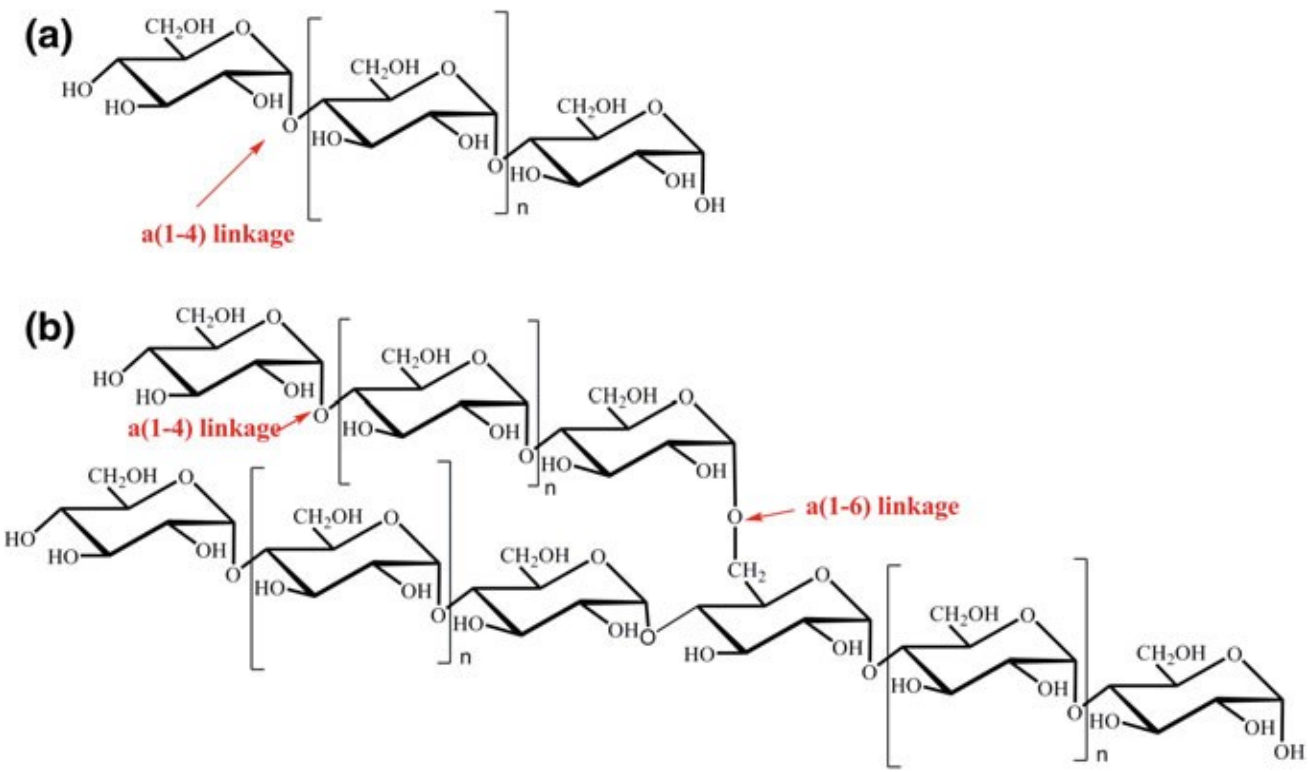

Fig. 3 Schematic diagram of chemical structures of starch: (a) amylose and (b) amylopectin [8]

Generally, starch can be found in four different crystalline structures [12, 21]:

- A-type: dry and warm conditions should be available to establish such structures in cereals. Starch chains are ordered in a double helix configuration with 6-glucose units per turning. These helices are ordered in unit cells containing 8-water molecules. 
- B-type: This structure is available in tubes obtained from starch resources with a high amylose content. It has a similar configuration of A-type with 36-water molecules per unit cell.

- C-type: It is a mixture of A and B types detected in most vegetables.

- V-type: It is found when small molecules such as fatty acid and iodine are available, The structure is a simple left helix with six glucose units per turning [12, 21].

\section{Preparation of starch nanocomposites}

Nanocomposites belong to a multiphase material system consisting of one or more components as continuous phases, which are called matrices like polymeric materials, as well as discontinuous phases $(<100 \mathrm{~nm})$ known as nanofillers. Nanofillers have an important role in improving structural, mechanical, thermal, and barrier properties by building new strong interactions with matrices [29-31]. For decades, researchers encountered many challenges for the preparation of starch nanocomposites because of their limited flexibility and high hydrophilicity apart from typical nanofiller agglomeration and weak interfacial bonding at high nanofiller loadings. Furthermore, many techniques are improved to overcome these disadvantages like using TPS instead of neat starch, modified nanofillers, coupling agents, compatibilisers [6]. For instance, He et al. [32] chemically modified halloysite nanotubes (HNTs) to prevent HNT agglomeration and achieved better particle dispersion within starch matrices. Weighted amounts of HNTs with polyethylene glycol (PEG) were suspended in distilled water. The suspension was mixed by using ball milling and then centrifuged for precipitation. The precipitated HNTs were rinsed with distilled water for several times to remove any free PEG, and then dried to obtain modified HNT powders. According to scanning electron microscopic (SEM) results, HNT aggregates can be broken up via ball milling, but they can be smashed simultaneously. The complete removal of chemical modifiers [32] or 
using natural modifiers like phosphatidylinositol (FPI) and citric acid [33, 34] is essential for materials used in the field of food packaging. Conventional preparation techniques have been implemented to prepare starch nanocomposites like extrusion, solution casting, compression and injection moulding [6, 8]. According to Madhumitha et al. [28] and Scarfato et al. [35] casting and extrusion are the most common manufacturing methods for material processing of starch as a non-thermoplastic polymer. As such, solution casting and extrusion are exclusively discussed in this section as the most popular processing methods.

\section{Casting}

Casting is more suitable for lab-scaled preparation process of starch nanocomposites. In this process, a starch aqueous solution with or without plasticisers and other additives is gelatinised at $85-90^{\circ} \mathrm{C}$ to prepare a homogenous suspension. Then equal amounts of suspension are poured into moulds to control the film thickness. After that, films are dried at temperatures between $30-50^{\circ} \mathrm{C}$ in an oven or at room temperature for at least $24 \mathrm{~h}[6,8,28]$. Nanofillers can be incorporated into starch matrices by different means. For instance, nanofillers suspension is prepared via sonication, ultrasonication and homogenisation to reduce nanofiller agglomeration, and then mixed gradually with gelatinised starch at moderate temperatures in range from $45-50^{\circ} \mathrm{C}$, as shown in Fig. 4. Majdzadeh-Ardakani et al. [36] studied the effect of mixing mode on the degree of clay dispersion within starch matrices. Starch suspension was prepared by heating $4 \mathrm{~g}$ starch with 10, 20 and $30 \mathrm{wt} \%$ glycerol in $60 \mathrm{ml}$ distilled water at $70^{\circ} \mathrm{C}$ for $1 \mathrm{~h}$ by using vigorous stirring. Montmorillonite (MMT) nanoclay suspension was prepared by mixing $5 \mathrm{wt} \%$ MMTs with $40 \mathrm{ml}$ distilled water in different modes, namely mechanical mixing for $1 \mathrm{~h}$ at $1600 \mathrm{rpm}$, sonication mixing for $1 \mathrm{~h}$ at the frequency of $20 \mathrm{kHz}$ and the combination of mechanical mixing and sonication mixing, each over the same period of 30 min. Nanoclay suspension was mixed with starch suspension at $70^{\circ} \mathrm{C}$ for $10 \mathrm{~min}$, and then heated under vacuum for $30 \mathrm{~min}$ at a boiling point of gelatinised starch. Their results showed 
that the combination of mechanical and sonication mixing mode gave rise to better nanoclay dispersion. Another approach is by adding starch granules to nanofiller suspension and gelatinised together. Sadegh-Hassani et al. [37] heated HNT suspension for $1 \mathrm{~h}$ with continuous stirring, which was then sonicated for 45 min for more homogenisation. HNT suspension was cooled to room temperature, and further starch powders were incorporated to prepare gelatinised starch nanocomposites. The solution was gelatinised at $85^{\circ} \mathrm{C}$ for $45 \mathrm{~min}$ prior to a gradual cooling process after being poured into the mould cavity for drying.

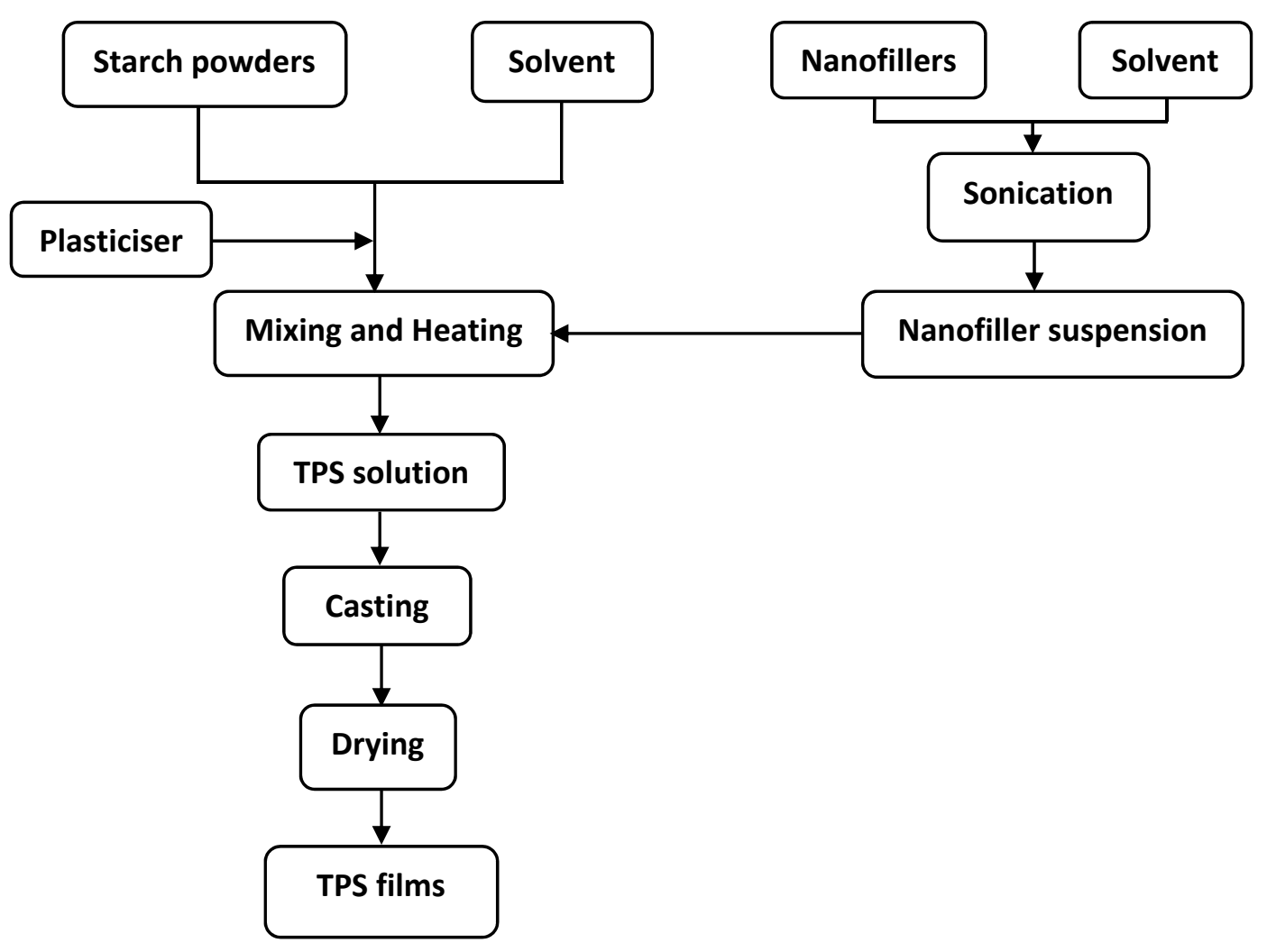

Fig. 4 Flow chart of processing TPS by solution casting

\section{Extrusion}

In the extrusion process, starch granule structures are broken down by the combination of pressure, heat and high shear forces to melt starch using a single or twin screw extruder. Under 
thermomechanical energy, starch granules are fragmented, restructured, plasticised, and melted to produce TPS, as shown in Fig. 5. This process becomes more difficult in the presence of nanofillers because nanofillers tend to easily clumped within starch matrices. All components (i.e. starch, nanofillers, and plasticisers) can be fed at a single stage to the extruder with or without water $[5,6,8,28]$. For instance, Schmitt et al. [11] mixed designated amounts of wheat starch, HNTs, glycerol and glycerol monostearate as plasticisers for $3 \mathrm{~h}$ in a mechanical mixer. Then these components were fed together into a twin screw extruder at $120^{\circ} \mathrm{C}$ and $60 \mathrm{rpm}$. Hietala et al. [38] premixed weighted amounts of starch, cellulose nanofibres (CNFs), sorbitol and stearic acid in the powder form. Subsequently, the mixture was fed in one step to a twin screw extruder at $200 \mathrm{rpm}$, depending on the moisture content of CNFs without additional water. Furthermore, hydrophilic nanofillers can be suspended in water and fed in subsequent extrusion process to the molten starch as the second stage [6, 8]. Dean et al. [39] studied three different ways for premixing components before the extrusion. These approaches included (i) a dry mixture of components was prepared by blending and further extrusion, (ii) clay suspension was prepared by conventional mixing, and then added to starch with subsequent extrusion, and (iii) clay suspension was prepared by sonication mixing, and then added to starch with the secondary process of extrusion. Depending on their results, sonication mixing was more suitable to disperse nanoclays at high nanofiller loadings.

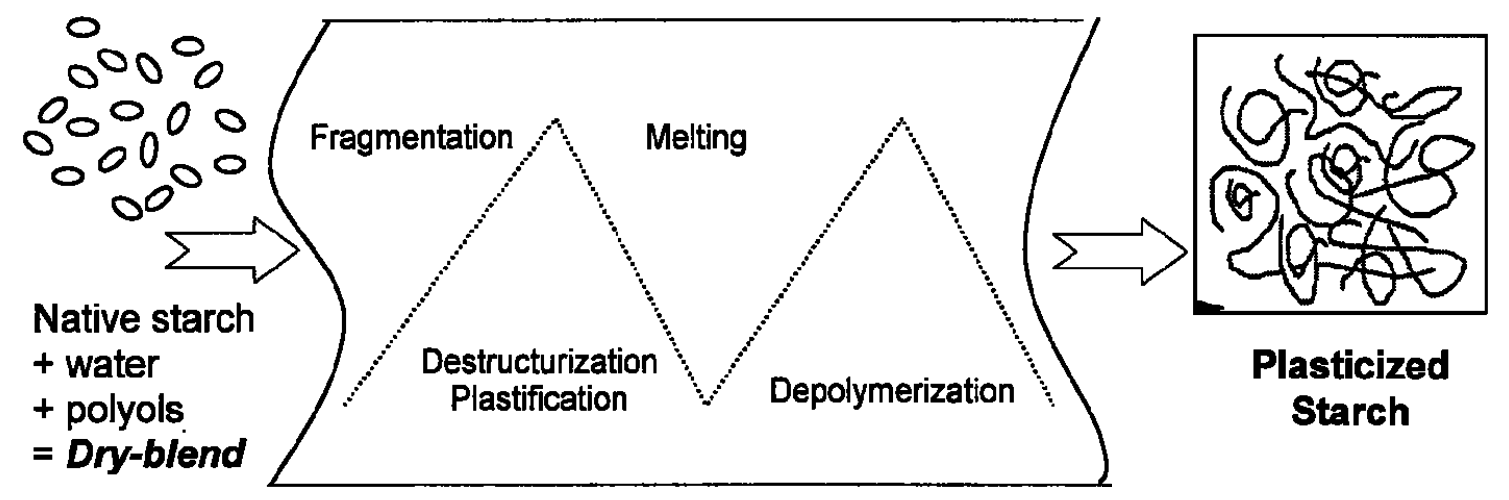

Fig. 5 Schematic diagram of processing TPS by extrusion [12] 
There are other techniques used to prepare nanocomposite materials. For instance, in-situ polymerisation can be employed when nanofillers are dispersed within monomers after the pretreatment with suitable chemical modifiers to improve filler dispersion in polymer matrices before the polymerisation. Light or heat can be used as an initiator for the polymerisation process $[5,6,40]$. The dispersion of nanofillers and their adhesion at polymer matrices/ nanofillers interfaces are the main effect on this process [40, 41]. Another technique is direct melting, in which nanofillers are incorporated in a molten polymer above $T_{g}$ or melting temperature, and then solidified at moderate temperatures $[5,10,41]$.

\section{Starch/clay nanocomposites}

Nanoclays can be classified as MMTs, HNTs, kaolinite, hectorite and bentonite according to their morphology and chemical composition [42]. MMT is one of popular phyllosilicate nanoclays [43]. Single MMT layer consists of one aluminium octahedron sheet between two silicate tetrahedron sheets with the layer thickness of approximately $1 \mathrm{~nm}$. MMT is compatible with water soluble polymers because of their hydrophilic characteristic [44, 45]. Lilichenko et al. [46] used MMTs to reinforce TPS. X-ray diffraction (XRD) analysis results showed that $d$ spacing was increased by $0.37 \mathrm{~nm}$ with the incorporation of $6 \mathrm{wt} \%$ MMTs due to intercalated nanoclay structures within TPS matrices. Furthermore, Young's modulus and tensile strength were increased by 2.6 and 1.9 folds, respectively at the MMT loading of $6 \mathrm{wt} \%$. However, elongation at break and moisture absorption were reduced by 43 and $0.5 \%$ accordingly. Chen and Evans [47] obtained similar XRD results when reinforcing TPS with MMTs. Nanocomposites showed a clear increasing trend of $d$-spacing from 1.23 to $1.80 \mathrm{~nm}$ with the incorporation of MMTs. It was evident that intercalated structures of nanocomposites occurred. According to Schlemmer et al. [48] exfoliated structures were predominant for nanoparticle dispersion of TPS/MMT nanocomposites with the MMT loading being less than $5 \mathrm{wt} \%$. 
However, intercalated structures were more pronounced when the MMT loading was beyond $5 \mathrm{wt} \%$. These results were apparently evidenced by XRD (see Fig. 6) and SEM analyses. Swain et al. [42] reported that the addition of 2 and $5 \mathrm{wt} \%$ Cloisite 30B MMTs produced intercalated structures within starch matrices. Nonetheless, the incorporation of 8 and $10 \mathrm{wt} \%$ nanoclays yielded typical exfoliated structures. Such findings were further confirmed by XRD and transmission electron microscopy (TEM), as illustrated in Fig. 7. In addition, decomposition temperatures of nanocomposites were increased by 15 and $20^{\circ} \mathrm{C}$ with the incorporation of 8 and $10 \mathrm{wt} \%$ Cloisite 30B MMTs, respectively. Besides, corresponding residual weights were enhanced by 20.5 and $27.0 \%$. On the other hand, the oxygen permeability (OP) of nanocomposites was reduced by $69.0 \%$ at the nanoclay loading of $10 \mathrm{wt} \%$ when compared with that of neat starch. Llanos and Tadini [49] demonstrated that the WVP and OP were increased by 1.5 and $32.0 \%$, respectively with the addition of $1 \mathrm{wt} \% \mathrm{MMT}-\mathrm{Na}^{+}$clays. Barrier properties are related to the material structure in the presence of nanofillers resulting in a gas tortuous path. As such, the WVP and OP were increased with increasing the porosity and change of material crystallinity when embedded with nanoclays. On the other hand, tensile strength, Young's modulus and elongation at break were improved by 18.75, 47.30 and $18.45 \%$, respectively with additional $0.5 \mathrm{wt} \% \mathrm{MMT}-\mathrm{Na}^{+}$clays. Furthermore, these properties were also enhanced by $31.25,2.80$ and $64.50 \%$ accordingly at the MMT- $\mathrm{Na}^{+}$loading of $1 \mathrm{wt} \%$ when compared with those of TPS. 


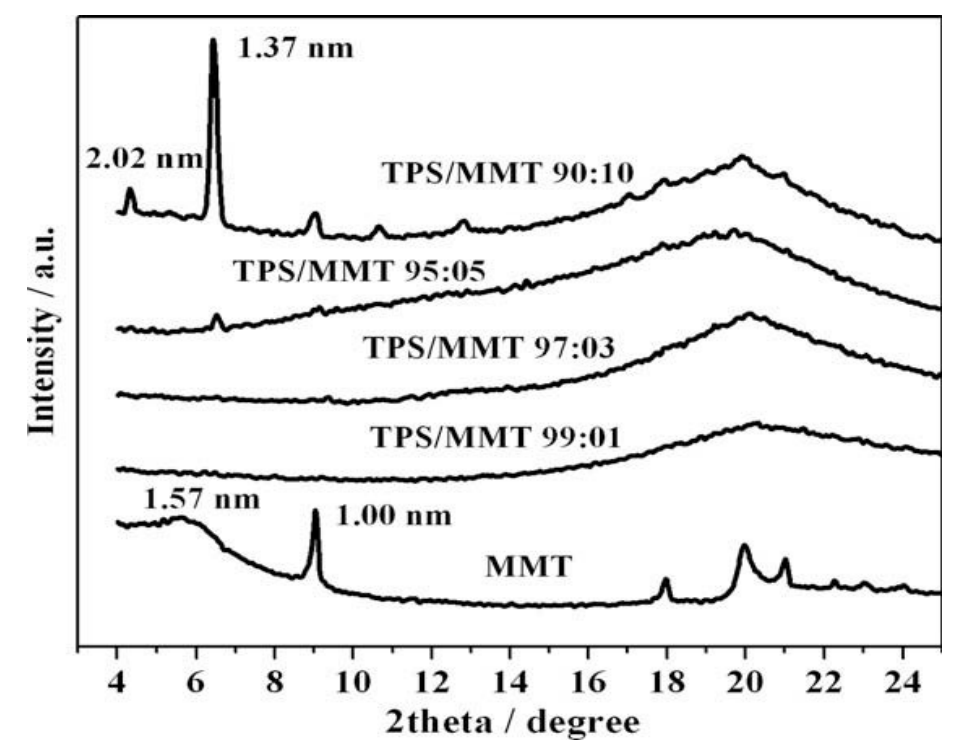

Fig. 6 XRD spectra of MMT nanoclays and TPS/MMT nanocomposites at different MMT loadings [48]

Majdzadeh-Ardakani et al. [36] used a Taguchi experimental approach to study the effect of the starch source, glycerol loading, nanoclay type and mixing mode on mechanical and morphological properties of starch/clay nanocomposites. By using wheat, potato and corn starch, the results showed that there was no significant effect of starch source on film performance. However, MMTs modified by citric acid presented better dispersion and mechanical properties compared with unmodified MMTs and Cloisite 30B nanoclays. The combination of mechanical and sonication mixing mode to disperse nanoclays was more effective than using an individual mode. Furthermore, TPS with $20 \mathrm{wt} \%$ glycerol was more homogeneous than those with 10 and $30 \mathrm{wt} \%$ glycerol. Park et al. [50] studied experimentally the effect of MMT type on TPS properties. Tensile results showed that the addition of $5 \mathrm{wt} \%$ Cloisite $\mathrm{Na}^{+}$clays increased tensile strength and Young's modulus by 27 and $21 \%$, respectively when compared with those of TPS. The reduction of WVP was also achieved due to its lower hydrophilicity, which is essential to maintain product quality and shelf life for material packaging. Surprisingly, there was no significant change in mechanical properties with the inclusion of Cloisite 6A, Cloisite10A, and Cloisite 30B MMTs. Issa et al. [51] showed that 
tensile strength, Young's modulus and elongation at break for TPS/MMT nanocomposites were increased by $138.4,876.0$ and $27.2 \%$ with the incorporation of $3 \mathrm{wt} \%$ MMTs compared with those of TPS. On the contrary, the WVP, solubility in water and biodegradation rates were reduced by 37,14 and 52\%, respectively for TPS $/ 3 \mathrm{wt} \%$ MMT nanocomposites as opposed to those of TPS due to the good interaction between matrices and nanofillers, which prevented water diffusion, reduced swollen molecules and improved material stiffness.
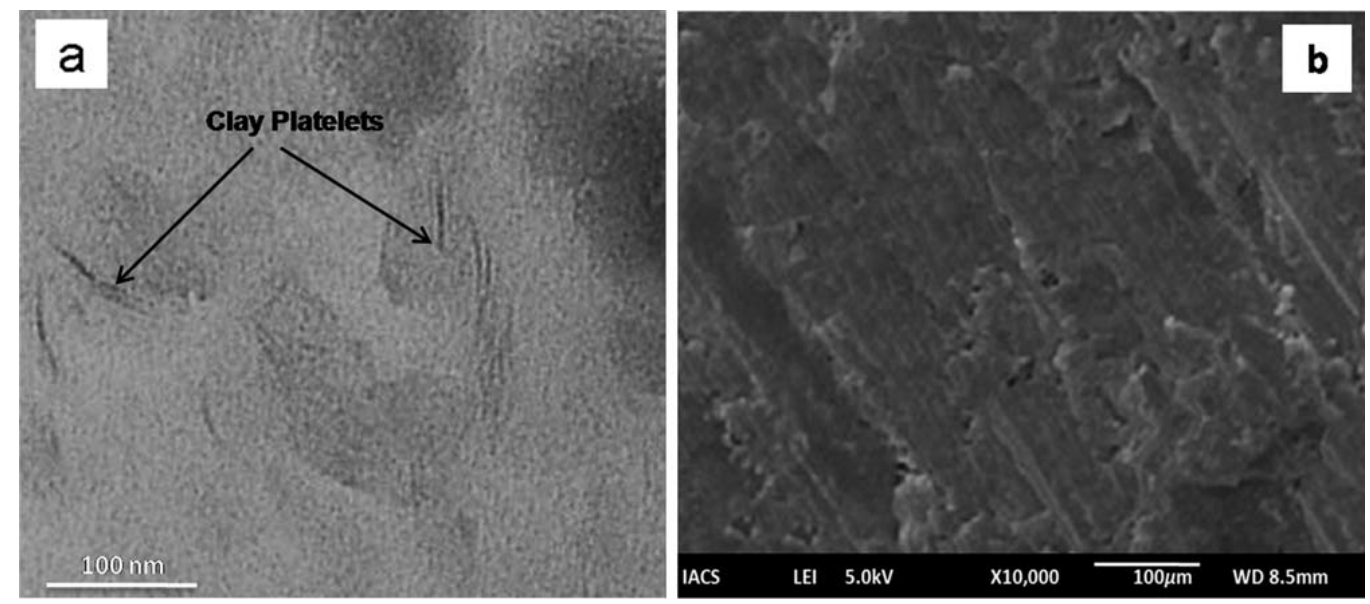

Fig. 7 (a) TEM and (b) SEM micrographs for exfoliated structures of starch/10 wt\% MMT nanocomposites [42]

HNTs are another example of nanoclays that are used widely to reinforced starch films. HNTs are in a tubular form of aluminosilicates based on a chemical formula $\mathrm{Al}_{2} \mathrm{Si}_{2} \mathrm{O}_{5}(\mathrm{OH})_{4} . n \mathrm{H}_{2} \mathrm{O}$ with the particle length between $500 \mathrm{~nm}-1.2 \mu \mathrm{m}$ and diameter less than $100 \mathrm{~nm}$. HNTs have a wide range of applications for medical science and material packaging due to their nontoxicity and biocompatibility nature $[52,53]$. Generally, it is used with starch to improve the material performance. For instance, He et al. [32] reported that tensile strength and Young's modulus of potato starch/HNT nanocomposite films with $20 \mathrm{wt} \%$ glycerol were increased linearly with increasing the modified HNT loading from 1 to $9 \mathrm{wt} \%$, as opposed to those of TPS counterparts. This is because the inherently high strength of HNTs created a strong hydrogen bonding between components. On the other hand, elongation at break was decreased due to the restricted 
mobility of polymeric chains for the same reason mentioned earlier. Furthermore, thermogravimetric analysis (TGA) results showed that the residual mass of starch films was increased with increasing the HNT loading. Sadegh-Hassani et al. [37] also prepared potato starch/HNT nanocomposite films with a sorbitol/glycerol mixture (mix ratio: 3:1) as plasticisers. Tensile strength and Young's modulus were improved by 34 and 100\%, respectively with increasing the HNT loading from 0 to $5 \mathrm{wt} \%$. Furthermore, elongation at break was reduced by $35 \%$ with additional $5 \mathrm{wt} \%$ HNTs. Nonetheless, the incorporation of HNTs diminished significantly both water absorption and solubility of films (Fig. 8) in addition to 71 and $50 \%$ reductions in WVP and OP, respectively. Such a phenomenon was associated with the effect of HNTs on diminishing the diffusion of molecules within the films. Xie et al. [54] also improved mechanical and barrier properties of TPS when incorporated with HNTs. Tensile strength was increased by $97 \%$ with increasing the HNT loading from 0 to $9 \mathrm{wt} \%$ while elongation at break was decreased by $71 \%$ as opposed to those of TPS. The WVP was decreased by 22.0 and $19.5 \%$ at the relative humidity (RH) of 75 and $100 \%$, respectively with increasing the HNT loading from 0 to $9 \mathrm{wt} \%$. Moreover, Meira et al. [55] found tensile strength, Young's modulus and decomposition temperature of TPS were enhanced by 79, 57 and 1\%, respectively with the addition of $3 \mathrm{wt} \% \mathrm{HNTs}$, and improved by 37,110 and $2 \%$ accordingly with the inclusion of $6 \mathrm{wt} \%$ HNTs. However, the solubility was found to be decreased by only 0.29 and $3.02 \%$ with the inclusion of 3 and $6 \mathrm{wt} \% \mathrm{HNTs}$, respectively when compared with that of TPS counterpart. Schmitt et al. [11] used unmodified HNTs and modified HNTs (MHNTs) with the quaternary ammonium salt and benzoalkonium chloride to reinforce wheat starch at the filler loadings of 2, 4, 6 and $8 \mathrm{wt} \%$. According to SEM results, the slight aggregation of both HNTs and MHNTs was evident at the HNT loading of $8 \mathrm{wt} \%$. However, this particle aggregation had little effect on mechanical properties of starch/HNT composites. The inclusion of 2- $8 \mathrm{wt} \%$ MHNTs increased Young's modulus and tensile strength by 89.7 
and $7.4 \%$, respectively. In contrast, the same loadings of unmodified HNTs increased tensile strength and Young's modulus by 20.8 and $79.8 \%$ accordingly. With both HNT types, elongation at break was contrarily decreased. Furthermore, the onset degradation temperature of gelatinised starch was delayed with the incorporation of HNTs.
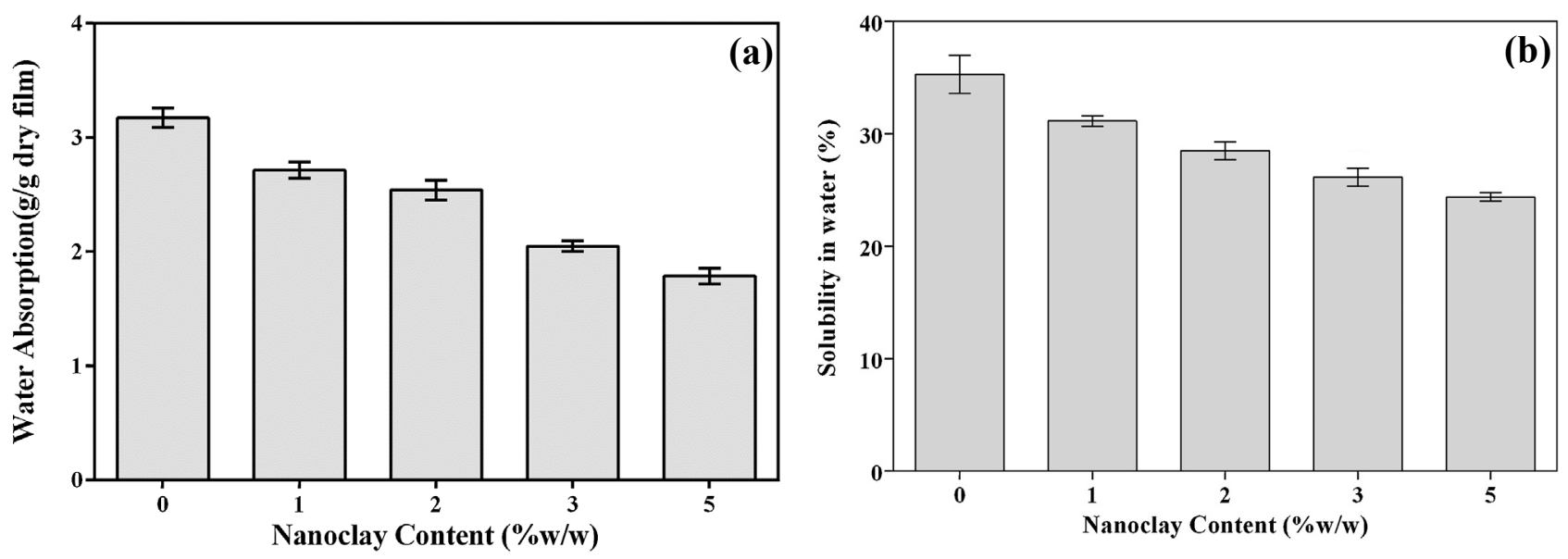

Fig. 8 Effect of HNT loading on: (a) water absorption and (b) water solubility of TPS nanocomposite films [37].

According to previous work, the incorporation of HNTs within TPS yielded higher tensile strength at different loadings as opposed to other clay types, illustrated in Fig. 9a. HNTs have very few number of hydroxyl groups on their surfaces in order to reduce tube-tube interaction and improve their dispersibility in polymers and other solvents [10]. As such, the modification of other nanoclay types such as MMTs can enhance their dispersibility with better mechanical strength. For instance, Huang and $\mathrm{Yu}$ [56] modified MMTs through the activation process. In this process, $1.462 \mathrm{~g}$ ethanolamine solution and $1.4 \mathrm{~mL}$ sulfuric acid were added to $700 \mathrm{~mL}$ water at $80^{\circ} \mathrm{C}$. This solution was added gradually to the MMT suspension in water, then the mixture was stirred at $80^{\circ} \mathrm{C}$ for $3 \mathrm{~h}$. After being cooled to room temperature, the mixture was filtered, dried, ground and finally sieved to prepare activated-MMTs. The incorporation of 2$11 \mathrm{wt} \%$ of activated-MMTs in TPS improved tensile strength linearly from 60 to $294 \%$ as compared with that of TPS counterpart. On the other hand, the inclusion of nanoclays with 
different loadings reduced the elongation at break as a result of the restricted mobility of polymeric chains, demonstrated in Fig. $9 b$.
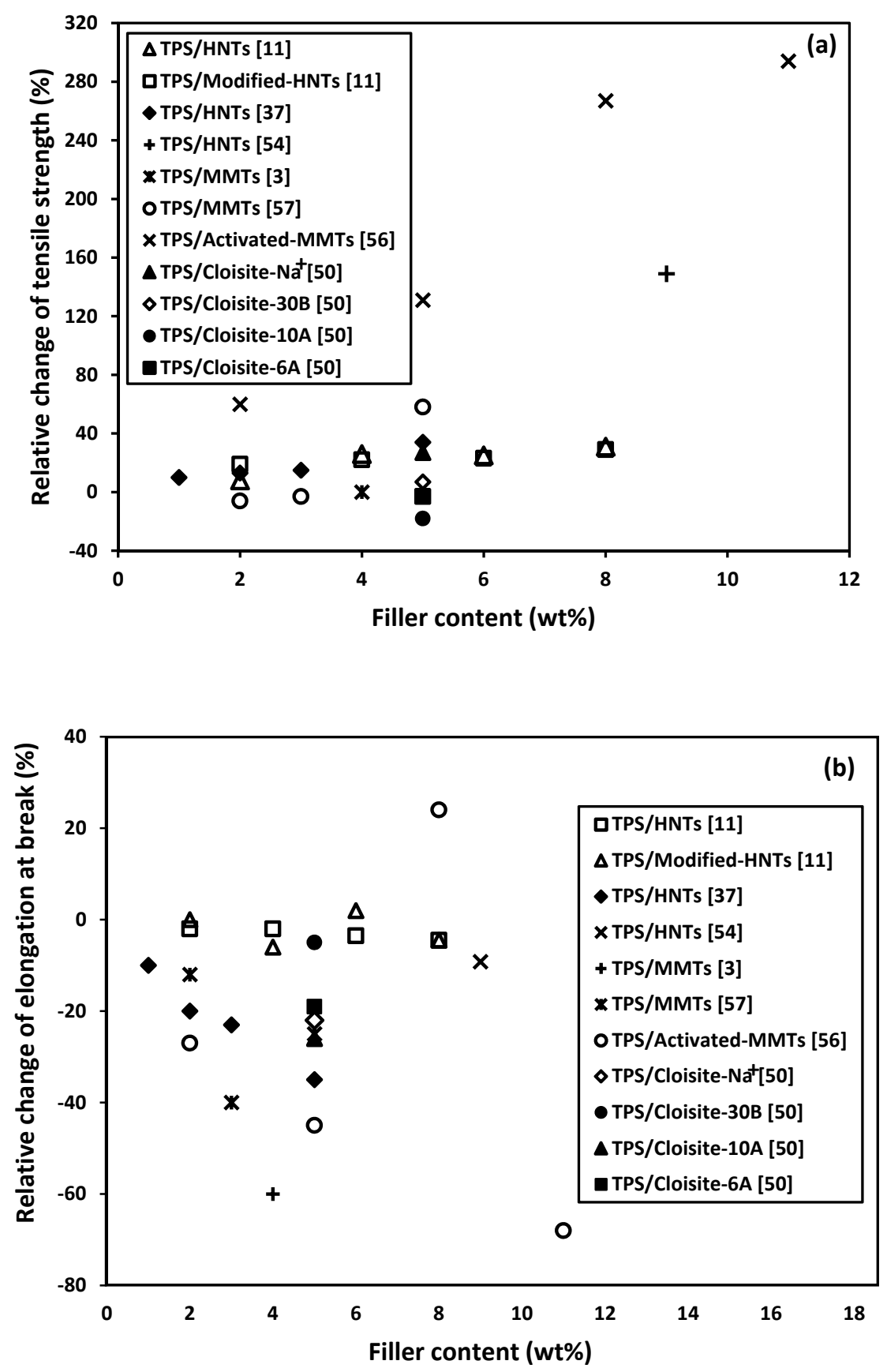

Fig. 9 Effect of filler content on (a) tensile strength and (b) elongation at break for TPS nanocomposites

\section{Starch/Polysaccharide Nanocomposites}

Polysaccharide nanofillers like cellulose and starch draw great attention, and are used to synthesise polymer bionanocomposites because of their renewability and complete 
biodegradability [20]. Cellulose is considered as the main component of plant cell walls and most abundant biomass on earth [27]. Cellulose nanofibres, nanoparticles, and nanowhiskers can be isolated from cotton, wood, jute, hemp, flax, peal hull, kenaf, ramie, etc. with diameters in range of 5-20 $\mathrm{nm}[5,27,43,58]$. Hietala et al. [38] showed that different CNF loadings (i.e., $5,10,15$ and $20 \mathrm{wt} \%$ ) had no effect on the moisture content of TPS/CNF composite films because of using sorbitol as the plasticiser with lower hydroxyl groups when compared with glycerol counterparts. This result was in good accordance with Teixeira et al. [59], indicating that the water uptake of TPS plasticised with a mixture of sorbitol/ glycerol (mix ratio: 1:1) was lower than that of TPS with glycerol, which was decreased only by $17.2 \%$ for the same reason mentioned earlier. Furthermore, water uptake was reduced by $32-37 \%$ for TPS plasticised with glycerol and $15-18 \%$ for TPS plasticised with sorbitol/glycerol with the inclusion of 5-20 wt\% CNFs. Svagan et al. [60] argued that the water uptake of TPS was reduced with increasing the CNF loading because CNFs had a higher degree of molecular ordering than TPS, thus making it less hygroscopic. Hence, the water uptake of TPS plasticised with $50 \mathrm{wt} \%$ was decreased from 7.5 to $3.9 \%$ with increasing the CNF content from 0 to 70 $w t \%$. Babaee et al. [61] compared the effect of modified CNFs, namely acetylated CNFs (ACNFs) and unmodified CNFs on TPS properties at a constant filler content of $10 \mathrm{wt} \%$. The WVP of nanocomposites was decreased by 14.0 and $1.6 \%$ with the inclusion of $10 \mathrm{wt} \% \mathrm{CNFs}$ and ACNFs, respectively. During an acetylation process of CNFs, some hydroxyl groups were replaced by acetyl groups, thus weakening the interfacial bonding between TPS and CNFs and resulting in the incorporation of more porous structures when compared with unmodified CNFs. For this reason, ACNFs gave rise to the WVP, which was lower than that of unmodified CNFs. Moreover, tensile strength and Young's modulus were increased by 341.8 and $749.3 \%$ with the addition of $10 \mathrm{wt} \%$ CNFs compared with those of TPS. A relatively small improvement of mechanical properties was achieved when incorporating ACNFs by increasing 
tensile strength and Young's modulus up to 71.0 and $78.3 \%$, respectively. Fungal degradation test result showed that TPS completely degraded after 30 days while TPS/CNFs and TPS/ACNFs required 40 and 60 days for the complete destruction. This finding could be related to the crystalline and denser structures of CNFs as opposed to that of TPS. Fabra et al. [62] reported that the WVP and OP were reduced by 51.8 and $93.0 \%$, respectively with the addition of $20 \mathrm{wt} \%$ bacteria cellulose nanowhiskers (BCNWs) within TPS. Different loadings of BCNWs in range from $2,5,10,15$ to $20 \mathrm{wt} \%$ had no impact on the transparency of TPS. Ma et al. [63] investigated the effect of carboxymethyl cellulose (CMC) and microcrystalline cellulose (MC) on thermal and barrier properties of TPS. The incorporation of $6 \mathrm{wt} \% \mathrm{CMCs}$ into TPS reduced thermal stability with decreasing the decomposition temperature by $19^{\circ} \mathrm{C}$, which was opposite to MCs with increasing the decomposition temperature by $6^{\circ} \mathrm{C}$ due to their microcrystalline structures (Fig. 10). Furthermore, the WVPs of TPS were decreased by 31.9 and $49.1 \%$ with the addition of $9 \mathrm{wt} \%$ CMCs and MCs, respectively, which was associated with their tortuous effect (Fig. 11).

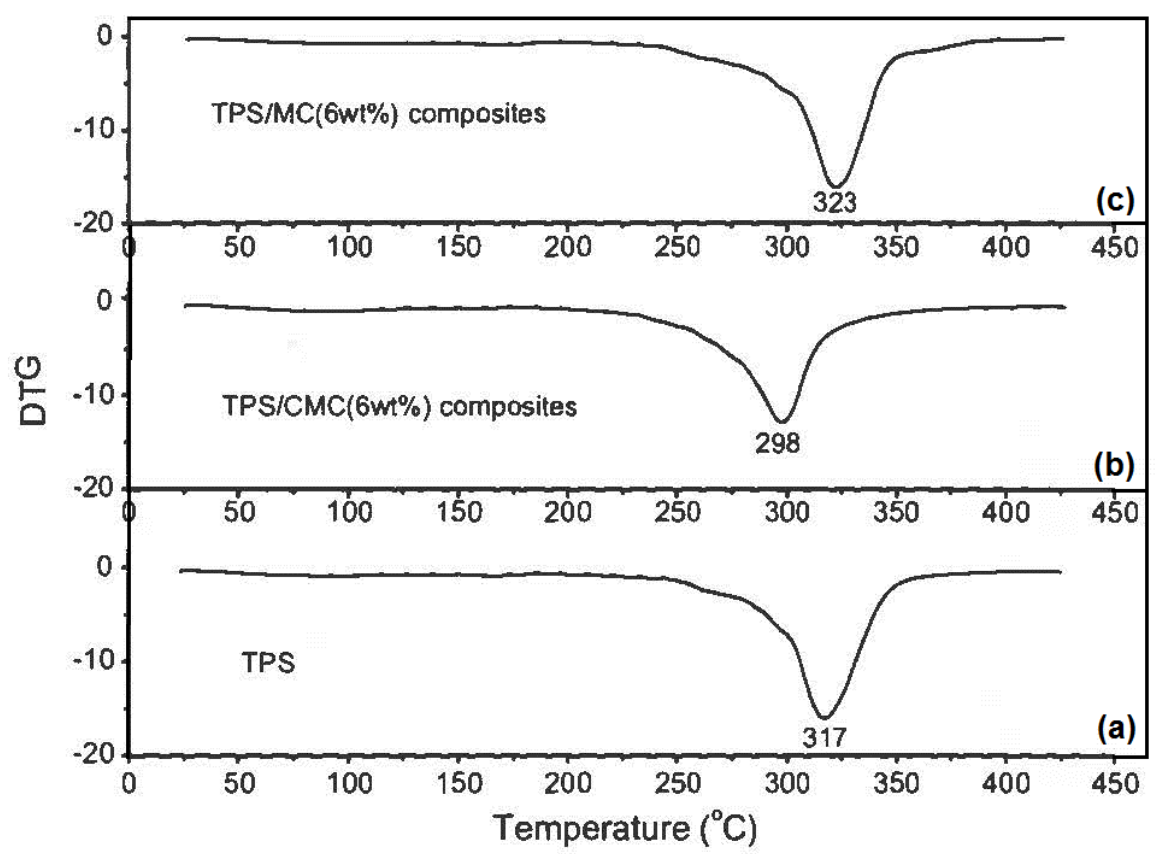

Fig. 10 DTG curves for decomposition temperature: (a) TPS, (b) TPS/carboxymethyl cellulose (CMC) composites, and (c) TPS/microcrystalline cellulose (MC) composites [63]. 
Kaushik et al. [64] reported that the thermal stability of TPS was increased with the incorporation of CNFs when decreasing the melting temperature of nanocomposites by 15.3 , 22.8 and $20.1^{\circ} \mathrm{C}$ at the $\mathrm{CNF}$ loadings of 5, 10 and $15 \mathrm{wt} \%$, respectively. Furthermore, melting enthalpies of nanocomposites were increased by 26.0 and $19.0 \mathrm{~J} \mathrm{~g}^{-1}$ at the CNF loadings of 5 and $10 \mathrm{wt} \%$ accordingly, which were then decreased by $2 \mathrm{~J} \mathrm{~g}^{-1}$ at $15 \mathrm{wt} \%$. Strong interfacial bonding between TPS and CNFs as well as good CNF dispersion were the main reason for all these improvements owing to the existence of new hydrogen bonding.

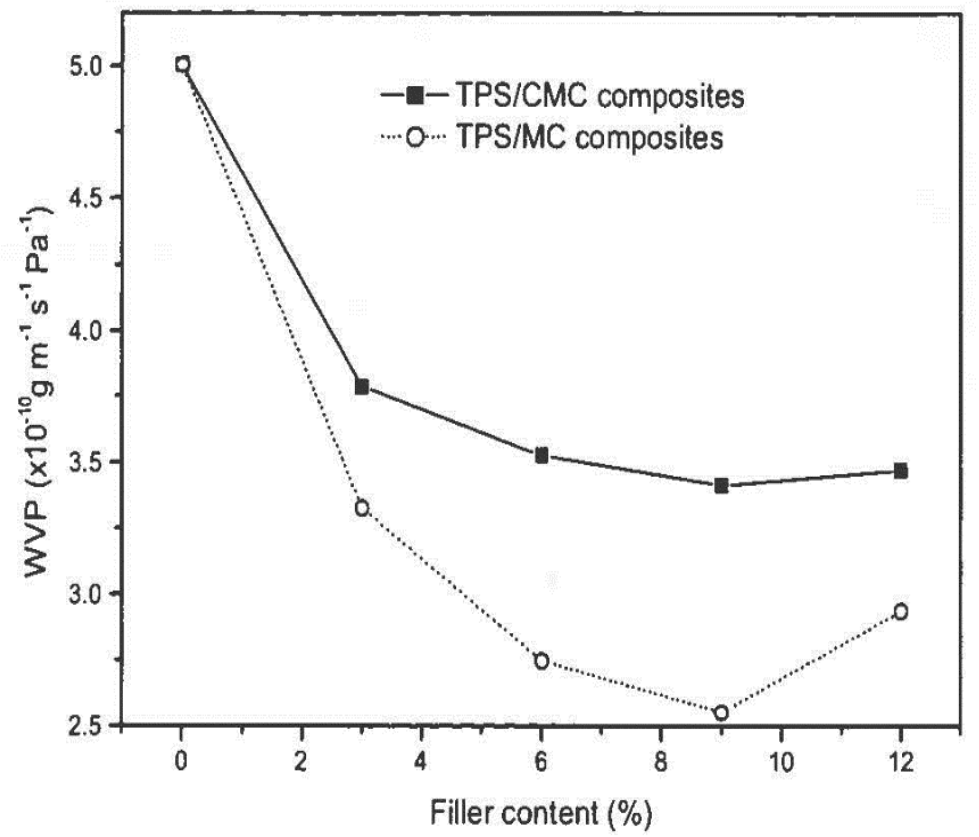

Fig. 11 Effect of CMC content on the WVP of TPS composites at different filler contents [63]

In general, cellulose fillers have the ability to form three-dimensional networks within polymer matrices in order to improve nanocomposite properties [65]. Consequently, tensile strength and Young's modulus were improved significantly with increasing the filler content, as summarised in Figs. 12a and 12b, while the elongation at break was decreased instead (Fig. 12c). When comparing the effect of cellulose fillers (e.g. CNFs, BCNWs, and cellulose nanocrystals $(\mathrm{CNCs}))$ on mechanical properties, it is clearly stated that $\mathrm{CNCs}$ induced 
relatively high tensile strength and Young's modulus of nanocomposites relative to CNFs and BCNWs at the same filler loading, as shown in Fig. 12a and 12b. This result can be interpreted according to high crystalline portion and uniform particle distribution of CNCs as opposed to other forms in good accordance with Sofla et al [66].
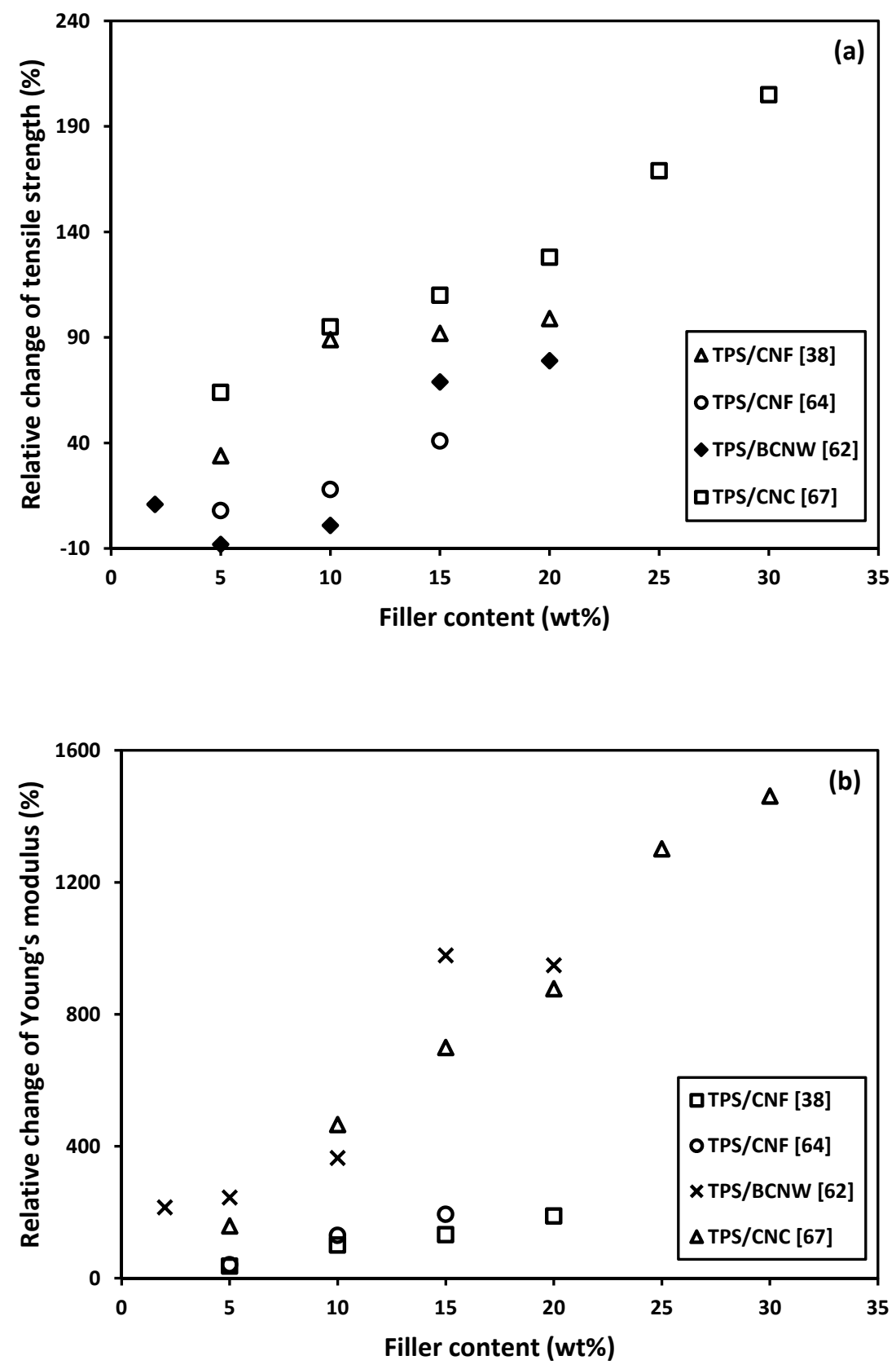


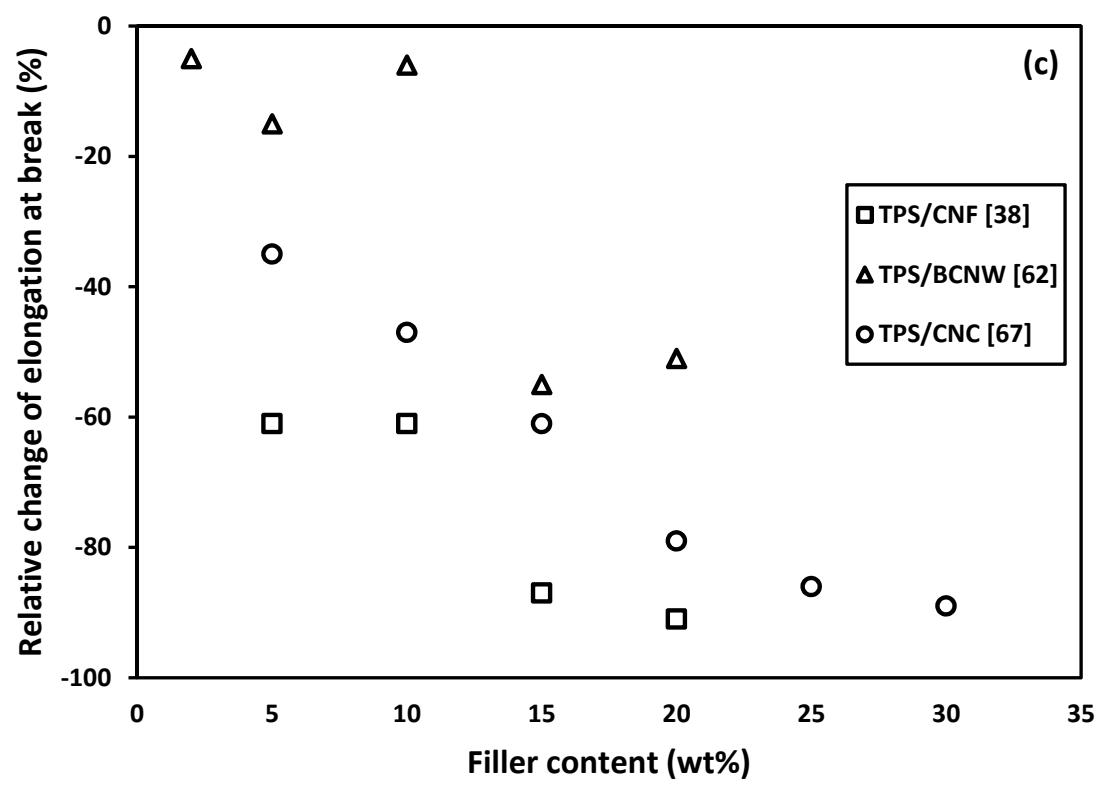

Fig. 12 Effect of filler content on (s) tensile strength, (b) Young's modulus, and (c) elongation at break for TPS nanocomposites.

Starch nanoparticles (SNPs) are also used as nanofillers to reinforce TPS. SNPs were prepared by the chemical treatment of native starch granules to produce nanoparticles with their diameters of 50-100 $\mathrm{nm}$ [43]. For instance, Ma et al. [68] studied the effect of pea and rice SNPs when modified with citric acid on mechanical, thermal and barrier properties of TPS. At different water contents, tensile properties were increased gradually with increasing starch nanoparticle contents due to good adhesive bonding with matrices, resulting from similar chemical characteristics, as illustrated in Fig. 13. Nonetheless, the decomposition temperature of TPS was decreased by 9.9 and $11.0^{\circ} \mathrm{C}$ with the addition of $12 \mathrm{wt} \%$ pea and rice SNPs, respectively, which was ascribed to the inherently weak thermal stability of starch. SNPs were transferred to hydrophilic particles after the modification with citric acid. Hence the WVPs were decreased by 47.5 and $59.2 \%$ with the inclusion of $12 \mathrm{wt} \%$ pea and rice SNPs, respectively. On the other hand, García et al. [69] found that the WVP was increased by $79 \%$ with the addition of $2.5 \mathrm{wt} \%$ waxy maize SNPs because of the interaction between 

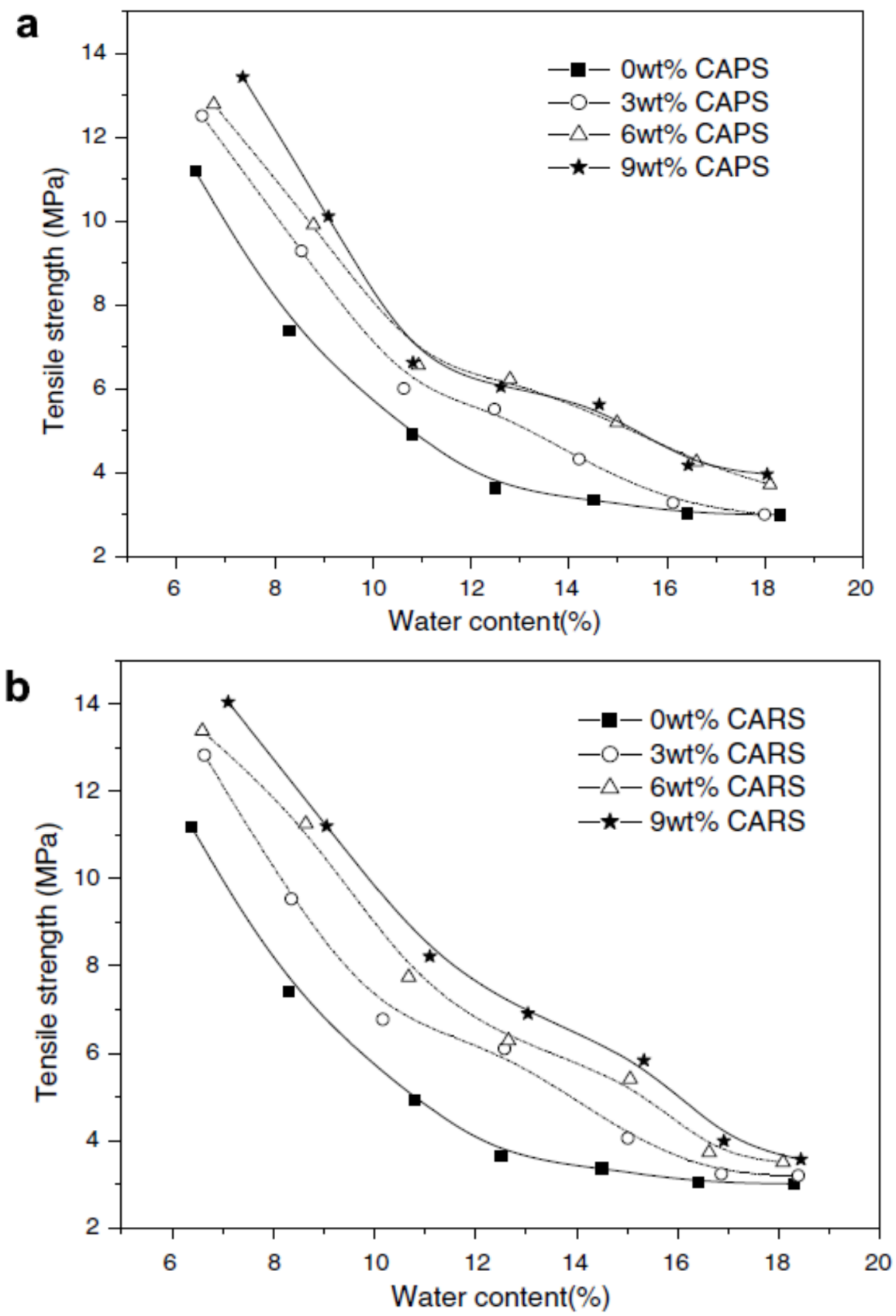

Fig. 13 Tensile strength of TPS nanocomposites at different water contents according to different loadings of (a) citric acid pea starch (CAPS) nanoparticles and (b) citric acid rice starch (CARS) nanoparticles [68].

nanoparticles and glycerol as a plasticiser, which was based on $\mathrm{OH}$ groups to create a good path for water diffusion and higher permeability. According to González et al. [70], tensile strength and Young's modulus of TPS were increased by 60 and $66 \%$, respectively when 
incorporated with $5 \mathrm{wt} \%$ waxy starch nanocrystals (WSNCs). However, the elongation at break and the OP of TPS appeared to be decreased by 9 and $66 \%$, respectively despite no significant change of WVP. In the same work, CNCs were used together with WSNCs to reinforce TPS. At 50/50 by weight for CNCs/WSNCs, Young's modulus and tensile strength were increased by 380 and $60 \%$, respectively though elongation at beak was decreased by $21 \%$. Hybrid nanocomposite showed higher OP by $17 \%$ compared with TPS due to increasing the hydrophilicity of materials. Guimarães et al. [71] reported the use of banana fibres to reinforce TPS with 30 wt\% glycerol as renewable materials. Young's moduli of TPS/banana fibre composites were increased by 186, 294 and $201 \%$ with the inclusion of 20,25 and $35 \mathrm{wt} \%$ banana fibres compared with that of TPS despite the retention of tensile strength. Such results suggested that the maximum fibre content to improve the material stiffness could be achieved at the banana fibre content of $25 \mathrm{wt} \%$, beyond which a typical reduction of Young's modulus was manifested. Additionally, the retention of tensile strength might be associated with the poor interfacial bonding between TPS and banana fibres.

\section{Starch/carbonaceous nanocomposites}

Carbon nanotubes (CNTs) have tubular structures and inherently excellent tensile properties (e.g., Young's modulus of approximately $1 \mathrm{TPa}$ and tensile strength of $150 \mathrm{GPa}$ ) [72]. Generally, CNTs are used to improve mechanical and electrical properties of petro-based and bio-based polymer nanocomposites [73, 74]. Single-walled CNTs (SWCNTs), double-walled CNTs (DWCNTs) and multi-walled CNTs (MWCNTs) are the main classes [75]. High agglomeration in polymer matrices and insolubility are major drawbacks of CNTs $[72,73,75]$. Non-ionic liquid surfactant TNWDIS as a dispersant was used by Cheng et al. [73] to overcome these problems. CNTs were oxidised to produce oxidised CNTs (OCNTs). Then they were reduced by glucose to prepare reduced CNTs (RCNTs). These three CNT types were employed 
to improve mechanical, barrier and electrical properties of TPS for non-food packaging applications. An addition of $4 \mathrm{wt} \%$ CNTs, OCNTs and RCNTs increased tensile strengths by $216.0,167.6$ and $401.2 \%$, respectively as opposed to that of TPS counterpart. Nonetheless, the WVP was decreased gradually with increasing the filler content, as depicted in Fig. 14. Moreover, electrical conductivity was improved by approximately 8 folds compared with TPS with additional $1 \mathrm{wt} \%$ CNTs. Famá et al. [76] added small amounts (i.e., 0.005, 0.010, 0.027 and $0.050 \mathrm{wt} \%$ ) of MWCNTs to TPS to be used as secondary packaging materials without having any direct contact with food. Dynamic mechanical properties and WVP were improved gradually with increasing the MWCNT loading. Storage modulus was detected to be increased by $100 \%$ and the WVP was decreased by $43 \%$ at the MWCNT loading of $0.050 \mathrm{wt} \%$.

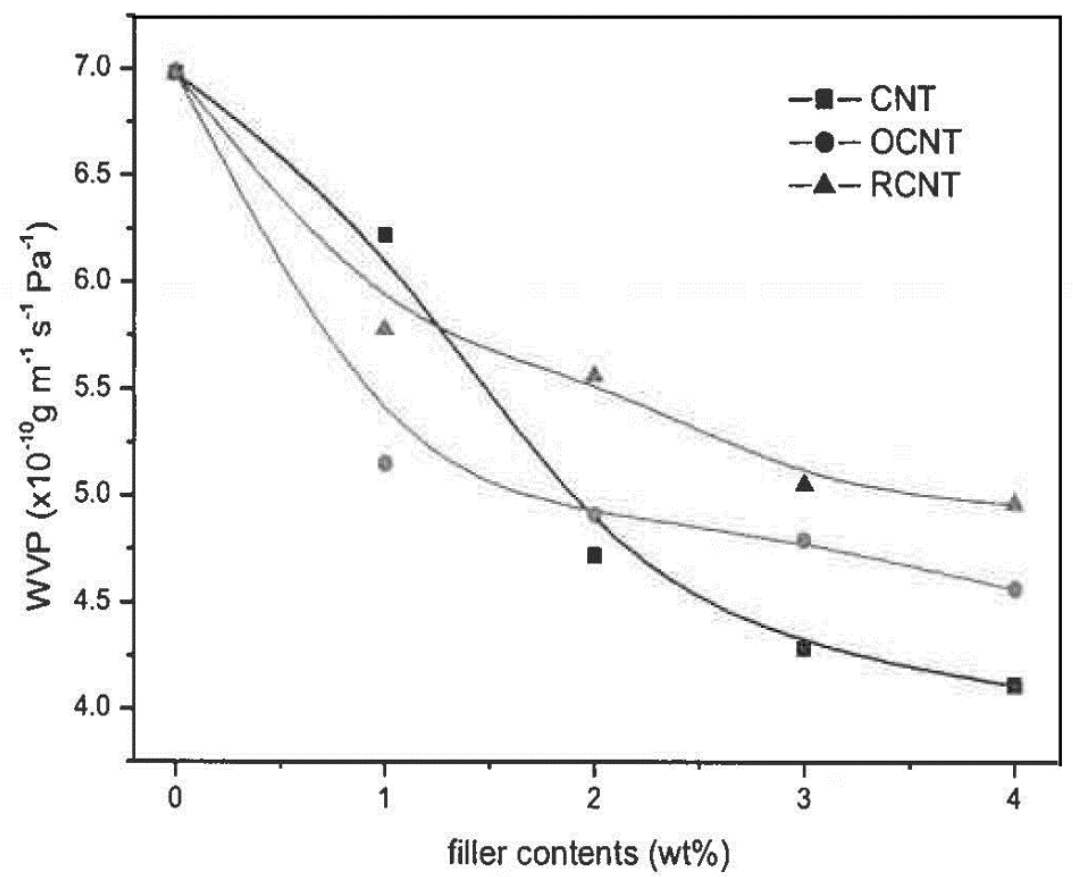

Fig. 14 WVP of TPS at different loadings of CNTs, OCNTs and RCNTs [73]. 
Graphene and graphene oxide (GO) are produced by oxidising natural graphite powders with a Hummers method [77, 78]. Graphene has a 2-dimensional structure of $\mathrm{sp}^{2}$-hybridised carbon molecules in hexagonal lattice $[79,80]$. Due to the presence of oxygen on the surface, GO has the ability to be dissolved in water and other polar solvents [44]. Graphene and GO have a high surface area, mechanical, thermal and electrical properties like CNTs with less agglomeration problem $[44,78,79]$. GOs have inherently impermeable to gases atoms [77]. Biocomposites reinforced with GOs can be used as UV-shielding packaging materials because of their high protection against the UV light [75-77]. For example, Li et al. [78] stated that the transmittance against UV light of TPS was decreased gradually to be as close as $0 \%$ with increasing the GO content from 0 to $2 \mathrm{wt} \%$. On the other hand, tensile strength and Young's modulus of TPS/GO nanocomposites were conversely increased by 202.4 and $854.5 \%$ accordingly. In addition, elongation at break was decreased by $66.4 \%$ at the same GO content level. Moreover, initial and final decomposition temperatures of TPS were also enhanced by 10.2 and $7.4^{\circ} \mathrm{C}$, respectively with increasing GO loadings from 0 to $2 \mathrm{wt} \%$ due to good dispersion within TPS matrices. Ma et al. [79] reduced oxygen-containing groups for GOs with the aid of glucose to produce reduced graphene oxides (RGOs), which were then used to reinforce TPS. GOs tended to agglomerate at the particle loading beyond $2 \mathrm{wt} \%$, which was lower than that of RGOs (i.e., $>6 \mathrm{wt} \%$ ) because RGOs contained fewer oxygen groups. Therefore, the tensile strength of TPS/GO nanocomposites reinforced with $2 \mathrm{wt} \%$ GOs was $13.1 \mathrm{MPa}$ when compared with 10.5 $\mathrm{MPa}$ for TPS/RGO nanocomposites with the inclusion of $6 \mathrm{wt} \%$ RGOs. This is because GOs form stronger hydrogen bonds with TPS due to abundant oxygen groups. Moreover, the WVP was reduced by $43.6 \%$ for TPS/GO nanocomposites and $34.8 \%$ for TPS/RGO nanocomposites with the addition of $4 \mathrm{wt} \%$ GOs and $8 \mathrm{wt} \%$ RGOs, respectively. In addition, the transmittance against the UV light of TPS was decreased to $0.24 \%$ with the inclusion of $2 \mathrm{wt} \%$ GOs without any clear UV absorbance of TPS/RGO nanocomposites. Zheng et al. [80] also reduced oxygen- 
containing GO groups in the presence of starch to produce starch-grafted graphene nanosheets (GN) starch for TPS reinforcements. The incorporation of $0.489 \mathrm{wt} \% \mathrm{GN}$-starch reduced the UV transmittance of TPS to $0.13 \%$. On the other hand, the incorporation of $1.774 \mathrm{wt} \% \mathrm{GN}$ starch increased tensile strength by $209.7 \%$ and electrical conductivity by 5 folds, along with the decreases in elongation at break and WVP by 84.0 and $43.3 \%$, respectively. These improvements were related to good nanofiller dispersion within polymer matrices in order to create much stronger interfacial bonding.

\section{Migration of constituents from nanocomposite packaging}

There is a considerable concern on food packaging sector about constituents' migration when nanocomposite systems are used in contact with food products $[35,81,82]$. Migration can be defined as the process of mass transfer when low-molecular-mass constituents of packaging materials are released into contained products [83-85]. This process consists of two steps: (i) the migration of constituents from the surface layers of packaging materials when directly contacted with the products and (ii) the migration of constituents from their interior layers depending on the structure of packaging materials like the presence of voids and gaps between polymer molecules [83]. Constituent migration rate depends on many factors such as its concentration, molecular weight, particle size, solubility and diffusivity, $\mathrm{pH}$ and temperature levels, material features of polymers like their density and viscosity, mechanical stresses and contact time between packaging materials and products $[3,83]$. According to Commission Regulation (EU) No.10/2011 86], the maximum migrated amount of constituents from packaging materials to food stuffs or simulants, namely overall migration limit (OML), should not exceed $10 \mathrm{mg} \mathrm{dm}^{-2}$ of packaging materials, which is equivalent to $60 \mathrm{mg} \mathrm{kg}^{-1}$ of food. The simplest test used to measure the migration rate is by contacting packaging materials with food stuffs or simulants at defined conditions associated with time and temperature. A suitable analytical techniques such as microscopy techniques (e.g. SEM, TEM, and atomic force 
microscopy (AFM)) for morphological structures and dispersion of nanofillers, spectroscopic technique (e.g. XRD) for elemental analysis, and quantitative analytical techniques (e.g. inductively coupled plasma mass (ICP-MS), atomic emission (ICP-AES)) are used at the end of tests to specify the amount of compound presented in the food stuffs or simulants $[3,82-84$, 87, 88]. Migration constituents can be nanofillers, plasticisers, and surfactants. Arvanitoyannis and Kotsanopoulos [89] reviewed many studies carried out on the migration of plasticisers, stabilisers, solvents and other additives from petro-based packaging materials and their effects on product properties. However, this area is still narrow for biopolymer-based nanocomposites particularly for starch nanocomposites. Table 2 summarised most migration studies that have been carried out on biopolymer nanocomposites.

Table 2 Migration tests for bionanocomposite system

\begin{tabular}{|c|c|c|c|c|}
\hline $\begin{array}{l}\text { Biopolymer } \\
\text { matrices }\end{array}$ & $\begin{array}{l}\text { Migrated } \\
\text { nanofillers }\end{array}$ & $\begin{array}{l}\text { Migration test } \\
\text { conditions }\end{array}$ & $\begin{array}{l}\text { Food stuff } \\
\text { /simulant }\end{array}$ & References \\
\hline Starch & MMT & $40^{\circ} \mathrm{C}$ and 10 day & Lattice, spinach & [3] \\
\hline Starch acetate & $\begin{array}{l}\text { Triacetin } \\
\text { (plasticizer) }\end{array}$ & $\begin{array}{l}\text { Room } \\
\text { temperature and } \\
300 \text { hours }\end{array}$ & Distilled water & [90] \\
\hline $\begin{array}{l}\text { TPS/aliphatic } \\
\text { polyester }\end{array}$ & $\begin{array}{l}\text { Carvacrol, } \\
\text { thymol, linalool } \\
\text { (Antimicrobial } \\
\text { agents) }\end{array}$ & $\begin{array}{l}15,25,35^{\circ} \mathrm{C} \text { and } \\
\text { time not } \\
\text { determined }\end{array}$ & Isooctane & [91] \\
\hline Starch-ester & Triacetin & $\begin{array}{l}\text { Microwave } \\
\text { heating at } 30^{\circ} \mathrm{C} \\
\text { for } 15,20,25,30 \text {, } \\
35 \text { min } \\
30^{\circ} \mathrm{C} \text { without } \\
\text { microwave for } 15 \text {, } \\
20,25,30,35 \text { min }\end{array}$ & $\begin{array}{l}\text { Whole and } \\
\text { skimmed milk }\end{array}$ & [92] \\
\hline Wheat gluten & MMT & $40^{\circ} \mathrm{C}$ and 10 days & $\begin{array}{l}\text { Distilled water, } \\
3 \% \text { acidic acid } \\
\text { solution, } 15 \% \\
\text { ethanol solution, } \\
\text { olive oil }\end{array}$ & [93] \\
\hline
\end{tabular}




\begin{tabular}{|c|c|c|c|c|}
\hline PLA & $\mathrm{Cu}$ & $\begin{array}{l}\text { Temperature not } \\
\text { available and 4-24 } \\
\text { hours }\end{array}$ & Saline solution & [94] \\
\hline PLA & $\mathrm{Ag}$ & $\begin{array}{l}\text { Room } \\
\text { temperature and } \\
1-8 \text { days }\end{array}$ & $\begin{array}{l}3 \% \text { nitric acid } \\
\text { solution }\end{array}$ & [95] \\
\hline PLA & $\mathrm{Ag}$ & $\begin{array}{l}\text { Temperature not } \\
\text { available and } \\
1,4,8,12,15 \text { days }\end{array}$ & $\begin{array}{l}4 \% \text { acidic acid } \\
\text { solution }\end{array}$ & [96] \\
\hline PLA & $\begin{array}{l}\text { Layered double } \\
\text { hydroxide }\end{array}$ & $40^{\circ} \mathrm{C}$ and 10 days & $\begin{array}{l}95 \% \quad \text { ethanol } \\
\text { solution }\end{array}$ & [97] \\
\hline PLA & $\begin{array}{l}\text { Cloisite- } \mathrm{Na}^{+} \\
\text {Cloisite-30B }\end{array}$ & $40^{\circ} \mathrm{C}$ and 10 days & $\begin{array}{l}95 \% \quad \text { ethanol } \\
\text { solution }\end{array}$ & [98] \\
\hline PLA & $\begin{array}{l}\text { Lactic Acid } \\
\text { (LA), lactide and } \\
\text { oligomers }\end{array}$ & $40^{\circ} \mathrm{C}$ and 10 days & $\begin{array}{l}\text { water, } 4 \% \text { acetic } \\
\text { acid solution or } \\
20 \% \text { ethanol } \\
\text { solution }\end{array}$ & [99] \\
\hline \multirow[t]{2}{*}{ PLA } & \multirow[t]{2}{*}{$\mathrm{LA}, \mathrm{CNC}$} & $40^{\circ} \mathrm{C}$ and 10 days & $\begin{array}{l}10 \% \quad \text { ethanol } \\
\text { solution }\end{array}$ & {$[100]$} \\
\hline & & $20^{\circ} \mathrm{C}$ and 2 days & Isooctane & \\
\hline \multirow[t]{2}{*}{ PLA } & \multirow{4}{*}{$\begin{array}{l}\text { LA, } \\
\text { Hydrogenated } \\
\text { amorphous } \\
\text { carbon }(\mathrm{a}-\mathrm{C}: \mathrm{H}) \\
\text { LA }\end{array}$} & $40^{\circ} \mathrm{C}$ and 10 days & $\begin{array}{l}10 \% \quad \text { ethanol } \\
\text { solution }\end{array}$ & {$[101]$} \\
\hline & & $20^{\circ} \mathrm{C}$ and 2 days & Isooctane & \\
\hline \multirow[t]{2}{*}{ PLA } & & $40^{\circ} \mathrm{C}$ and 10 days & $\begin{array}{l}3 \% \text { acetic acid } \\
\text { solution, } 50 \% \\
\text { ethanol solution }\end{array}$ & {$[102]$} \\
\hline & & $\begin{array}{l}40^{\circ} \mathrm{C} \text { and } 1,3,5, \\
10 \text { days }\end{array}$ & $\begin{array}{l}50 \% \text { ethanol } \\
\text { solution }\end{array}$ & \\
\hline
\end{tabular}

Störmer et al. [103] stated that the manufacturing method of nanocomposite materials played an important role in the migration of nanofillers. When nanofillers are completely embedded within polymer matrices, there is no potential for the migration into products. For nanocomposite materials manufactured by extrusion, blowing and injection moulding, there is no direct contact between nanofillers and products because all nanofillers are embedded within 
Table 3 Migration rates of starch-based films at different temperatures [91]

\begin{tabular}{|c|c|c|c|}
\hline \multirow[t]{2}{*}{ AM agent } & \multirow[t]{2}{*}{ Temperature $\left({ }^{\circ} \mathrm{C}\right)$} & $\begin{array}{l}\text { Heat pressed APTPS } \\
\text { film }\end{array}$ & \multirow{2}{*}{$\begin{array}{l}\text { MC-HPMC coating } \\
\text { of starch-based film } \\
\begin{array}{l}\text { Migration rate } \\
\left(v_{0} \times 10^{-4} \mathrm{~g} \mathrm{~s}^{-1}\right)\end{array}\end{array}$} \\
\hline & & $\begin{array}{ll}\text { Migration } & \text { rate } \\
\left(v_{0} \times 10^{-4} \mathrm{~g} \mathrm{~s}^{-1}\right) & \end{array}$ & \\
\hline \multirow[t]{3}{*}{ Linalool } & 15 & 0.1 & 0.3 \\
\hline & 25 & 0.2 & 0.4 \\
\hline & 35 & 0.4 & 0.7 \\
\hline \multirow[t]{3}{*}{ Carvacrol } & 15 & 0.2 & 1.2 \\
\hline & 25 & 0.3 & 1.8 \\
\hline & 35 & 0.5 & 3.6 \\
\hline \multirow[t]{3}{*}{ Thymol } & 15 & 0.1 & 0.8 \\
\hline & 25 & 0.2 & 1.2 \\
\hline & 35 & 0.6 & 3.1 \\
\hline
\end{tabular}

Note that $v_{0}$ is the rate of release or migration of antimicrobial (AM) agents for TPS blend films.

continuous polymer matrices and only those on the surface would be covered with thin layers of polymers [103]. Avella et al. [3] studied the migration of MMTs from starch to lettuce and spinach. The migration test was conducted on starch $/ 4 \mathrm{wt} \%$ MMT nanocomposite bags at $40^{\circ} \mathrm{C}$ for 10 days. At the end of tests, the lattice content of $\mathrm{Fe}, \mathrm{Mg}$, and $\mathrm{Si}$ was increased by 0.68 , 0.69 , and $5.78 \%$, respectively. In comparison, the spinach content of $\mathrm{Fe}, \mathrm{Mg}$, and $\mathrm{Si}$ was increased by $0.12,0.39$, and $5.33 \%$, respectively. These results are still within an acceptable range of OML at $60 \mathrm{mg} \mathrm{kg}^{-1}$. Moreover, Kuorwel et al. [91] investigated the temperature effect on the migration rate of three different antimicrobial (AM) agents, namely carvacrol, thymol and linalool from heat pressed TPS/aliphatic polyester (APTPS) blend films before and after being coated with methylcellulose (MC) and hydroxypropyl methylcellulose (HPMC). Migration tests were carried out at 15,25 and $35^{\circ} \mathrm{C}$ with isooctane being a fatty-food simulant on different time intervals. In general, the migration rate of AM agents was increased with 
increasing the temperature from 15 to $35^{\circ} \mathrm{C}$ for starch-based blends before and after coating. However, it was lower for coating films when compared with uncoated counterparts, as shown in Table 3. Increasing the migration rate of AM agents is related to the improvement of AM molecular mobility at high temperature levels.

Huang et al. [92] obtained the similar result when studying the effect of microwave treatment on the triacetin (plasticiser) migration from starch ester films. The migration test was conducted at $30{ }^{\circ} \mathrm{C}$ with the microwave treatment at the heating rate of $2{ }^{\circ} \mathrm{C} \min ^{-1}$ for $15,20,25,30$ and 35 min by using both whole milk and skimmed milk. The same conditions were employed without the microwave treatment for corresponding control films. The triacetin content in starch ester films was decreased dramatically with time in both whole and skimmed milk (with or without microwave treatment). Nonetheless, the migration rate was more rapid with microwave treatment, resulting in the acceleration of migration rate, as shown in Fig. 15. Moreover, Zhu et al. [90] studied the migration of triacetin from starch acetate films at room temperature for $300 \mathrm{~h}$ by using distilled water. Their results indicated that the plasticiser content in the films was decreased with the time in spite of being still within an acceptable range.

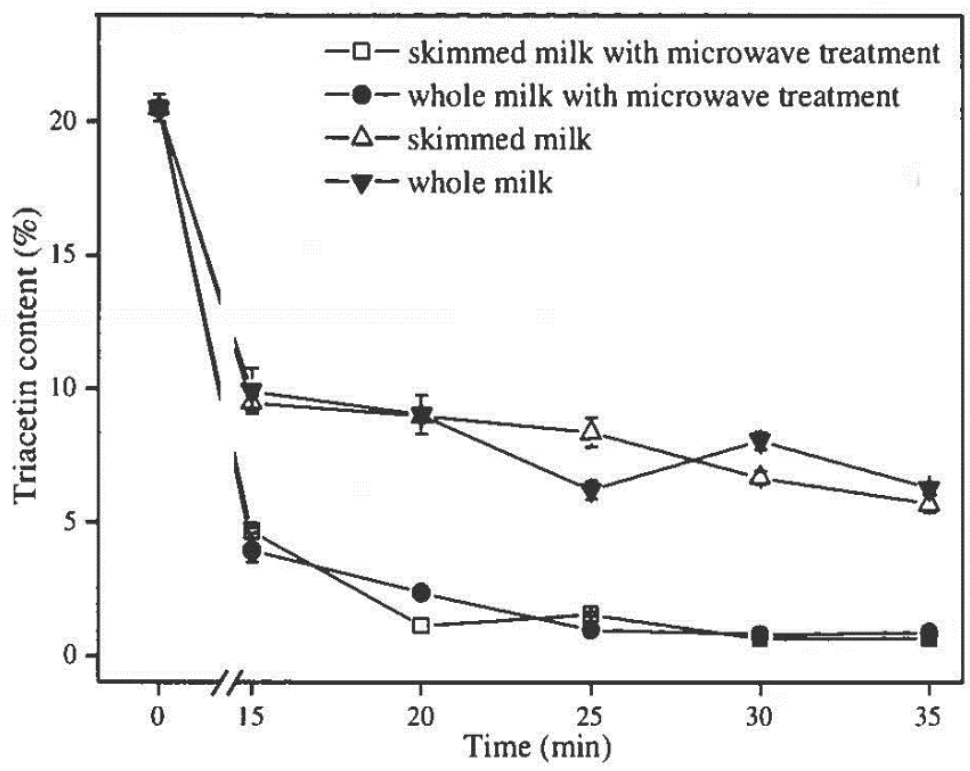

Fig. 15 Effect of microwave treatment on the plasticiser content of starch ester films [92]. 
Adhikari et al. [104] found that the plasticisers used with biopolymers had effect on the moisture migration. The effect of glycerol, xylitol and their mixture were tested on the moisture migration from TPS. $10 \mathrm{wt} \%$ glycerol appeared to have less impact on the moisture migration when compared with the same content of xylitol due to the high affinity between glycerol and water to improve the water binding. On the other hand, a high plasticiser content of $15 \mathrm{wt} \%$ or above increased the rate of moisture migration due to increasing the mobility of TPS molecular chains. As a result, the presence of plasticiser is essential to improve the flexibility of starchbased materials. However, a suitable plasticiser content should be chosen to prevent the moisture migration.

\section{Future trend of starch nanocomposites}

The environmental concern, technological development and exhaustion of petro-based polymer resources are deemed to be a driving force for detecting new polymeric resources. Ecofriendly polymers, particularly biopolymers, have drawn great attention in last few decades. Starch is one of such popular biopolymers as the alternative owing to its availability in nature, costeffectiveness and biodegradability.

As far as starch nanocomposites are concerned, researchers overcome several limitations for widespread applications of starch such as limited flexibility, low mechanical and thermal properties in addition to high moisture sensitivity. Further efforts have to be made for advancing starch nanocomposite systems by means of the manipulation of nanofiller and plasticiser contents in order to reduce the permeability and moisture sensitivity, and meanwhile maintain or improve corresponding mechanical and thermal properties. The migration of nanocomposite constituents is another important aspect worth mentioning for the purpose of limiting the health and hygienic risks when such packaging materials are in direct contact with food stuffs. 
Nowadays, starch and its nanocomposites have been widely used in packaging, medical, pharmaceutical, agricultural industries. The major challenges encountered in next decades lie in higher commercial demands for raw materials based on starch resources, requirements of technological innovation to develop starch hybrid nanocomposites with excellent material performance and more cost-effectiveness at an industrial mass-production level.

\section{Summary}

Starch structures and sources were reviewed in this paper as one of renewable and complete biodegradable polymers. Replacing starch with TPS is essential to overcome the brittleness problem of neat starch. Casting and extrusion were discussed with details as the most popular manufacturing techniques for TPS nanocomposites. Good nanofiller dispersion within TPS matrices is an essential issue for manufacturing TPS nanocomposites. Nanoclays, polysaccharides and carbonaceous were used as nanofillers for TPS to improve its multifaceted material performance. Small loadings of nanofillers were found to be more effective to improve tensile, thermal and barrier properties of nanocomposites because good particle dispersion along with strong interfacial bonding between nanofillers and matrices can be easily achieved. The partial hydrophobicity of HNTs makes their dispersion within TPS matrices much easier as opposed to unmodified MMTs as hydrophilic nanoclays. Consequently, modified MMTs can be used to overcome such an issue. Although cellulose fillers have hydrophilic nature, barrier properties of TPS/cellulose nanocomposites are improved due to the high interaction between components to produce three-dimensional networks. Starch fillers can improve tensile properties and almost reduce thermal and barrier properties due to the inherent brittleness, low thermal stability and hydrophilicity of starch, respectively. TPS/carbonaceous nanocomposites are used as shielding packaging materials owing to their high protection against the UV lights when carbonaceous nanofillers are incorporated in addition to the enhancement of mechanical, 
thermal and electrical properties. The migration of nanofillers is still limited to TPS nanocomposite systems. The future trend of starch nanocomposites relies on the good balance of material performance and cost with the upscaling of industrial manufacturing.

\section{Acknowledgements}

The Higher Committee for Developing Education (HCDE) in Iraq is acknowledged for funding this research through a PhD scholarship awarded to Zainab W. Abdullah at Curtin University.

\section{References}

1. Parra D, Tadini C, Ponce P, Lugao A (2004) Mechanical properties and water vapour transmission in some blends of cassava starch edible films. Carbohyd Polym 58(4): $475-481$.

2. Silvestre C, Duraccio D, Cimmino S, (2011) Food packaging based on polymer nanomaterials. Prog Polym Sci 36:1766-1782.

3. Avella M, Vlieger J J, Errico M E, Fischer S, Vacca P, Volpe M G (2005) Biodegradable starch/clay nanocomposite films for food packaging applications. Food Chem 93(3):467-474.

4. Petersson M, Stading M (2005) Water vapour permeability and mechanical properties of mixed starch-monoglyceride films and effect of film forming conditions. Food Hydrocolloid 19(1):123-132.

5. Medeiros E S, Dufresne A, Orts W J (2010) Starch-based nanocomposites. In: Bertolini, AC (ed) Starches: characterization, properties, and applications. Boca Raton: Taylor \& Francis, New York, pp 205-251.

6. Dong P, Prasanth R, Xu F, Wang X, Li B, Shankar R (2015) Eco-friendly Polymer Nanocomposite-Properties and Processing. In: Thakur V K, Thakur M K (eds) 
Advanced Structured Materials Eco-friendly Polymer Nanocomposites. Springer: New Delhi, pp75, 1-15.

7. Famá L M, Goyanes S, Pettarin V, Bernal C R (2015) Mechanical Behavior of StarchCarbon Nanotubes Composites. In: Kar K K, Jitendra K, Rana P S (eds) Handbook of Polymer Nanocomposites. Processing, Performance and Application. Springer: New York, pp141-171.

8. García NL, Famá L, D’Accorso NB, Goyanes S (2015) Biodegradable Starch Nanocomposites. In: Thakur V K, Thakur M K (eds) Advanced Structured Materials Eco-friendly Polymer Nanocomposites. Springer: New Delhi, pp75, 17-77.

9. Sam S T, Nuradibah M A, Chin K M, Hani N (2015) Current Application and Challenges on Packaging Industry Based on Natural Polymer Blending. In: Olatunji O (ed) Natural Polymers Industry Techniques and Applications. Springer: New York, pp163-184.

10. Abdullah Z W, Dong Y, Davies I J, Barbhuiya S (2017) PVA, PVA Blends, and Their Nanocomposites for Biodegradable Packaging Application. Polym-Plast. Technol Eng 56(12):1307-1344.

11. Schmitt H, Prashantha K, Soulestin J, Lacrampe M, Krawczak P (2012) Preparation and properties of novel melt-blended halloysite nanotubes/wheat starch nanocomposites. Carbohyd Polym. 89(3):920-927.

12. Avérous L, Halley P J (2009) Biocomposites based on plasticized starch. Biofuels Bioprod Bioref. 3:329-343.

13. Khan B, Niazi M B, Samin G, Jahan Z (2016) Thermoplastic Starch: A Possible Biodegradable Food Packaging Material-A Review. J Food Process Eng 40(3):1-16. 
14. Visakh P M (2016) Starch: State-of-the-Art, New Challenges and Opportunities. In: Visakh $\mathrm{P} \quad \mathrm{M}, \quad \mathrm{Yu} \mathrm{L}$ (eds) Starch-based Blends, Composites and Nanocomposites, Cambridge: Royal Society of Chemistry. pp 1-16.

15. Paes S S, Yakimets I, Mitchell J R (2008) Influence of gelatinization process on functional properties of cassava starch films. Food Hydrocolloid 22(5):788-797.

16. Talja R A, Helén H, Roos Y H, Jouppila K (2007) Effect of various polyols and polyol contents on physical and mechanical properties of potato starch-based films. Carbohyd Polym 67(3):288-295.

17. Shi R, Zhang Z, Liu Q, Han Y, Zhang L, Chen D, Tian W (2007) Characterization of citric acid/glycerol co-plasticized thermoplastic starch prepared by melt blending. Carbohyd Polym 69(4):748-755.

18. Reddy N, Yang Y (2010) Citric acid cross-linking of starch films. Food Chem 118(3):702-711.

19. Avérous L (2004) Biodegradable Multiphase Systems Based on Plasticized Starch: A Review. J Macromol Sci Part C 44(3):231-274.

20. Corre DL, Bras J, Dufresne A (2010) Starch Nanoparticles: A Review. Biomacromol 11(5):1139-1153.

21. Tester R F, Karkalas J, Qi X (2004) Starch-composition, fine structure and architecture. J Cereal Sci 39(2):151-165.

22. Romero-Bastida C A, Bello-Pérez L A, García M A, Martino M N, Solorza-Feria J, Zaritzky N E (2005) Physicochemical and microstructural characterization of films prepared by thermal and cold gelatinization from non-conventional sources of starches. Carbohyd Polym 60(2):235-244.

23. Galdeano M C, Mali S, Grossmann M V, Yamashita F, García M A (2009) Effects of plasticizers on the properties of oat starch films. Mater Sci Eng C 29(2):532-538. 
24. Robyt J F (2008) Starch: Structure, properties, chemistry, and enzymology. In: FraserReid B, Tatsuta K, Thiem J (eds) Glycoscience. Springer-Verlag: Berlin Heidelberg, pp1437-1472.

25. Medeiros E S, Dufresne A, Orts W J (2010) Starch-based nanocomposites. In: Bertolini A C (eds) Starch Characterisation, Properties and Applications. Taylor and Francis Group, USA, pp205- 251.

26. Buléon A, Colonna P, Planchot V, Ball S (1998) Starch granules: structure and biosynthesis. Int J Biol Macromol 23(2):85-112.

27. Olatunji O (2015) Classification of Natural Polymers. In: Olatunji O (eds) Natural Polymers Industry Techniques and Applications. Springer: New York, pp1-17.

28. Madhumitha G, Fowsiya J, Roopan S M, Thakur V K (2018) Recent advances in starchclay nanocomposites. Int J Polym Anal Cha 1-15.

doi:10.1080/1023666x.2018.1447260

29. Liu H, Xie F, Yu L, Chen L, Li L (2009) Thermal processing of starch-based polymers. Prog Polym Sci 34:1348-1368.

30. Rhim J, Ng P K (2007) Natural Biopolymer-Based Nanocomposite Films for Packaging Applications. Crit Rev Food Sci 47(4):411-433.

31. Othman S H (2014) Bio-nanocomposite Materials for Food Packaging Applications: Types of Biopolymer and Nano-sized Filler. Agr Agr Sci Procedia 2:296-303.

32. He Y, Kong W, Wang W, Liu T, Liu Y, Gong Q, Gao J (2012) Modified natural halloysite/potato starch composite films. Carbohyd Polym 87(4):2706-2711.

33. Yoon S, Chough S, Park H (2006) Properties of starch-based blend films using citric acid as additive. II. J Appl Polym Sci 100(3):2554-2560. 
34. Nyankson E, Olasehinde O, John V T, Gupta R B (2015) Surfactant-Loaded Halloysite Clay Nanotube Dispersants for Crude Oil Spill Remediation. Ind Eng Chem Res 54(38):9328-9341.

35. Scarfato P, Maio L D, Incarnato L (2015) Recent advances and migration issues in biodegradable polymers from renewable sources for food packaging. J Appl Polym Sci 132(48). doi:10.1002/app.42597

36. Majdzadeh-Ardakani K, Navarchian A H, Sadeghi F (2010) Optimization of mechanical properties of thermoplastic starch/clay nanocomposites. Carbohyd Polym 79(3):547-554.

37. Sadegh-Hassani F, Nafchi A M (2014) Preparation and characterization of bionanocomposite films based on potato starch/halloysite nanoclay. Int $\mathrm{J}$ Biol Macromol 67:458-462.

38. Hietala M, Mathew A P, Oksman K (2013) Bionanocomposites of thermoplastic starch and cellulose nanofibers manufactured using twin-screw extrusion. Eur Polym J 49(4):950-956.

39. Dean K, Yu L, Wu D Y (2007) Preparation and characterization of melt-extruded thermoplastic starch/clay nanocomposites. Compos Sci Technol 67(3-4):413-421.

40. Zou H, Wu S, Shen J (2008) Polymer/Silica Nanocomposites: Preparation, Characterization, Properties, and Applications. Chem Rev 108:3893-3957.

41. Wei L, Hu N, Zhang Y (2010) Synthesis of Polymer-Mesoporous Silica Nanocomposites. Materials 3(7):4066-4079.

42. Swain S K, Patra S K, Kisku S K (2013) Study of thermal, oxygen-barrier, fire-retardant and biodegradable properties of starch bionanocomposites. Polym Compos 35(7):12381243. 
43. Xie F, Pollet E, Halley P J, Avérous L (2013) Starch-based nano-biocomposites. Prog Polym Sci 38(10-11):1590-1628.

44. Raheel M, Yao K, Gong J, Chen X, Liu D, Lin, Y et al. (2014) Poly(vinyl alcohol)/GOMMT nanocomposites: Preparation, structure and properties. Chinese J Polym Sci 33(2):329-338.

45. Sapalidis A A, Katsaros F K, Kanellopoulos N K (2011) PVA/montmorillonite nanocomposites: Development and properties. In: Cuppoletti J (eds) Nanocomposites and Polymers with Analytical Methods. In Tech: Rijeka, pp. 29-50.

46. Lilichenko N, Maksimov R D, Zicans J, Meri R M, Plume E (2008) A biodegradable polymer nanocomposite: Mechanical and barrier properties. Mech Compos Mater $44(1): 45-56$.

47. Chen B, Evans J R (2005) Thermoplastic starch-clay nanocomposites and their characteristics. Carbohyd Polym 61(4):455-463.

48. Schlemmer D, Angélica R S, Sales M J (2010) Morphological and thermomechanical characterization of thermoplastic starch/montmorillonite nanocomposites. Compos Struct 92(9):2066-2070.

49. Llanos J H, Tadini C C (2018) Preparation and characterization of bio-nanocomposite films based on cassava starch or chitosan, reinforced with montmorillonite or bamboo nanofibers. Int J Biol Macromol 107:371-382.

50. Park H, Li X, Jin C, Park C, Cho W, Ha C (2002) Preparation and Properties of Biodegradable Thermoplastic Starch/Clay Hybrids. Macromol Mater Eng 287(8):553558.

51. Issa A T, Schimmel K A, Worku M, Shahbazi A, Ibrahim S A, Tahergorabi R (2018) Sweet Potato Starch-Based Nanocomposites: Development, Characterization, and Biodegradability. Starch- Stärke 1700273 (1- 8). doi:10.1002/star.201700273 
52. Schmitt H, Creton N, Prashantha K, Soulestin J, Lacrampe M, Krawczak P (2014) Meltblended halloysite nanotubes/wheat starch nanocomposites as drug delivery system. Polym Eng Sci 55(3):573-580.

53. Schmitt H, Creton N, Prashantha K, Soulestin J, Lacrampe M, Krawczak P (2014) Preparation and characterization of plasticized starch/halloysite porous nanocomposites possibly suitable for biomedical applications. J Appl Polym Sci 132(4) 41341. https://doi.org/10.1002/app.41341.

54. Xie Y, Chang P R, Wang S, Yu J, Ma X (2011) Preparation and properties of halloysite nanotubes/plasticized Dioscorea opposita Thunb. Starch composites. Carbohyd Polym 83(1):186-191.

55. Meira S M, Zehetmeyer G, Scheibel J M, Werner J O, Brandelli A (2016) Starchhalloysite nanocomposites containing nisin: Characterization and inhibition of Listeria monocytogenes in soft cheese. LWT- Food Sci Technol 68:226-234.

56. Huang M, Yu J (2005) Structure and properties of thermoplastic corn starch/montmorillonite biodegradable composites. J App Polym Sci 99(1):170-176.

57. Cyras V P, Manfredi L B, Ton-That M, Vázquez A, (2008) Physical and mechanical properties of thermoplastic starch/montmorillonite nanocomposite films. Carbohyd Polym 73(1):55-63.

58. Liu D, Sun X, Tian H, Maiti S, Ma Z (2013) Effects of cellulose nanofibrils on the structure and properties on PVA nanocomposites. Cellulose 20(6):2981-2989.

59. Teixeira E D, Pasquini D, Curvelo A A, Corradini E, Belgacem M N, Dufresne A (2009) Cassava bagasse cellulose nanofibrils reinforced thermoplastic cassava starch. Carbohyd Polym 78(3):422-431.

60. Svagan A J, Hedenqvist M S, Berglund L (2009) Reduced water vapour sorption in cellulose nanocomposites with starch matrix. Compos Sci Technol 69(3-4):500-506. 
61. Babaee M, Jonoobi M, Hamzeh Y, Ashori A (2015) Biodegradability and mechanical properties of reinforced starch nanocomposites using cellulose nanofibers. Carbohyd Polym 132 (1-8). doi:10.1016/j.carbpol.2015.06.043

62. Fabra M J, López-Rubio A, Ambrosio-Martín J, Lagaron J M (2016) Improving the barrier properties of thermoplastic corn starch-based films containing bacterial cellulose nanowhiskers by means of PHA electrospun coatings of interest in food packaging. Food Hydrocolloid 61:261-268.

63. Ma X, Chang P R, Yu J (2008) Properties of biodegradable thermoplastic pea starch/carboxymethyl cellulose and pea starch/microcrystalline cellulose composites. Carbohyd. Polym 72(3):369-375.

64. Kaushik A, Singh M, Verma, G (2010) Green nanocomposites based on thermoplastic starch and steam exploded cellulose nanofibrils from wheat straw. Carbohyd Polym $82(2): 337-345$.

65. Aloui H, Khwaldia K, Hamdi M, Fortunati E, Kenny J M, Buonocore G G, Lavorgna M (2016) Synergistic Effect of Halloysite and Cellulose Nanocrystals on the Functional Properties of PVA Based Nanocomposites. ACS Sustain Chem Eng 4(3):794-800.

66. Sofla M R, Brown R J, Tsuzuki T, Rainey T J (2016) A comparison of cellulose nanocrystals and cellulose nanofibres extracted from bagasse using acid and ball milling methods. Adv Nat Sci Nanosci Nanotechnol 7(3):035004.

67. Cao X, Chen Y, Chang P R, Muir A D, Falk G (2008) Starch-based nanocomposites reinforced with flax cellulose nanocrystals. Express Polym Let 2(7):502-510.

68. Ma X, Chang P R, Yu J, Stumborg M (2009) Properties of biodegradable citric acidmodified granular starch/thermoplastic pea starch composites. Carbohyd Polym 75(1):1-8. 
69. García N L, Ribba L, Dufresne A, Aranguren M, Goyanes S (2011) Effect of glycerol on the morphology of nanocomposites made from thermoplastic starch and starch nanocrystals. Carbohyd Polym 84(1):203-210.

70. González K, Retegi A, González A, Eceiza A, Gabilondo N (2015) Starch and cellulose nanocrystals together into thermoplastic starch bionanocomposites. Carbohyd Polym 117:83-90.

71. Guimarães J. Wypych F, Saul C, Ramos L, Satyanarayana K (2010) Studies of the processing and characterization of corn starch and its composites with banana and sugarcane fibers from Brazil. Carbohyd. Polym 80(1):130-138.

72. Liu L, Barber A H, Nuriel S, Wagner H D (2005) Mechanical Properties of Functionalized Single-Walled Carbon-Nanotube/ Poly(vinyl-alcohol) Nanocomposites. Adv Funct Mater 15(6):975-980.

73. Cheng J. Zheng P, Zhao F, Ma X (2013) The composites based on plasticized starch and carbon nanotubes. Int J Bio. Macromol 59:13-19.

74. Koinkar P, Kumar A, Avasthi D K, More M, Murakami R (2015) The High Energy Ion Irradiation Impact on Carbon Nanotubes. In: Kar K K, Jitendra K, Rana P S (eds) Handbook of Polymer Nanocomposites. Processing, Performance and Application. Springer: New York. pp 1-12.

75. Park S, Lee S, Jin F (2015) Surface Modification of Carbon Nanotubes for HighPerformance Polymer Composites. In: Kar K K, Jitendra K, Rana P S (eds) Handbook of Polymer Nanocomposites. Processing, Performance and Application. Springer: New York, pp13-59.

76. Famá L, Rojo P G, Bernal C, Goyanes S, Biodegradable starch based nanocomposites with low water vapour permeability and high storage modulus. Carbohyd Polym 87(3):1989-1993. 
77. Kim H M, Lee J K, Lee H S (2011) Transparent and high gas barrier films based on poly(vinyl alcohol)/graphene oxide composites. Thin Solid Films 519(22):7766-7771.

78. Li R, Liu C, Ma J (2011) Studies on the properties of graphene oxide-reinforced starch biocomposites. Carbohyd Polym 84(1):631-637.

79. Ma T, Chang P R, Zheng P, Ma X (2013) The composites based on plasticized starch and graphene oxide/reduced graphene oxide. Carbohyd Polym 94(1):63-70.

80. Zheng P, Ma T, Ma X (2013) Fabrication and Properties of Starch-Grafted Graphene Nanosheet/Plasticized-Starch Composites. Ind Eng Chem Res 52(39):14201-14207.

81. Maisanaba S, Pichardo S, Jordá-Beneyto M, Aucejo S, Cameán A M, Jos Á (2014) Cytotoxicity and mutagenicity studies on migration extracts from nanocomposites with potential use in food packaging. Food Chem Toxicol 66:366-372.

82. Echegoyen Y, Rodríguez S, Nerín C (2016) Nanoclay migration from food packaging materials. Food Add Contam A 33(3):530-539.

83. Huang J, Li X, Zhou W (2015) Safety assessment of nanocomposite for food packaging application. Trend Food Sci Technol 45(2):187-199.

84. Souza V G, Fernando A L (2016) Nanoparticles in food packaging: Biodegradability and potential migration to food-A review. Food Packag. Shelf Life 8:63-70.

85. Arvanitoyannis I S, Bosnea L (2004) Migration of Substances from Food Packaging Materials to Foods. Crit Rev Food Sci 44(2):63-76.

86. European Union (2011) Commission Regulation (EU) No. 10/2011 of 14 of January 2011 on Plastic Materials and Articles Intended to Come in Contact with Food. Off J Eur Union L12:1-89.

87. Adhikari B, Chaudhary D, Clearfeuille E (2009) The effect of starch-plasticiser(s) interactions on the moisture migration behavior of plasticised low amylose-starch films 
[online]. In: Engineering Our Future: Are We up to the Challenge? 27- 30 September 2009, Burswood Entertainment Complex. Barton, ACT: Engineers Australia, 725-734.

88. Noonan G O, Whelton A J, Carlander D, Duncan T V (2014) Measurement Methods to Evaluate Engineered Nanomaterial Release from Food Contact Materials. Compr Rev Food Sci F 13(4):679-692.

89. Arvanitoyannis I S, Kotsanopoulos K V (2013) Migration Phenomenon in Food Packaging. Food-Package Interactions, Mechanisms, Types of Migrants, Testing and Relative Legislation-A Review. Food Bioprocess Technol 7(1):21-36.

90. Zhu J, Li X, Huang C, Chen L, Li L (2014) Structural changes and triacetin migration of starch acetate film contacting with distilled water as food simulant. Carbohyd Polym 104:1-7. doi:10.1016/j.carbpol.2013.12.087

91. Kuorwel K K, Cran M J, Sonneveld K, Miltz J, Bigger S W (2013) Migration of antimicrobial agents from starch-based films into a food simulant. LWT-Food Sci Technol 50(2):432-438.

92. Huang C, Zhu J, Chen L, Li L, Li X (2014) Structural changes and plasticizer migration of starch-based food packaging material contacting with milk during microwave heating. Food Control 36(1):55-62.

93. Mauricio-Iglesias M, Peyron S, Guillard V, Gontard N (2010) Wheat gluten nanocomposite films as food-contact materials: Migration tests and impact of a novel food stabilization technology (high pressure). J App Polym Sci 116:2526-2535.

94. Conte A, Longano D, Costa C, Ditaranto N, Ancona A, Cioffi N et al. (2013) A novel preservation technique applied to fiordilatte cheese. Innov Food Sci Emerg 19:158-165.

95. Busolo M A, Fernandez P, Ocio M J, Lagaron J M (2010) Novel silver-based nanoclay as an antimicrobial in polylactic acid food packaging coatings. Food Add Contam A 27(11):1617-1626. 
96. Girdthep S, Worajittiphon P, Molloy R, Lumyong S, Leejarkpai T, Punyodom W (2014) Biodegradable nanocomposite blown films based on poly(lactic acid) containing silver-loaded kaolinite: A route to controlling moisture barrier property and silver ion release with a prediction of extended shelf life of dried longan. Polymer 55(26):67766788.

97. Schmidt B, Katiyar V, Plackett D, Larsen E, Gerds N, Koch C B, Petersen J (2011) Migration of nanosized layered double hydroxide platelets from polylactide nanocomposite films. Food Addit Contam A 28(7):956-966.

98. Schmidt B, Petersen J, Koch C B, Plackett D, Johansen N, Katiyar V, Larsen E (2009) Combining asymmetrical flow field-flow fractionation with light-scattering and inductively coupled plasma mass spectrometric detection for characterization of nanoclay used in biopolymer nanocomposites. Food Addit Contam A 26(12):16191627.

99. Mutsuga M, Kawamura Y, Tanamoto K (2008) Migration of lactic acid, lactide and oligomers from polylactide food-contact materials. Food Addit Contam A 25(10):12831290.

100. Fortunati E, Peltzer M, Armentano I, Torre L, Jiménez A, Kenny J (2012) Effects of modified cellulose nanocrystals on the barrier and migration properties of PLA nanobiocomposites. Carbohyd. Polym. 90(2):948-956.

101. Mattioli S, Peltzer M, Fortunati E, Armentano I, Jiménez A, Kenny J (2013) Structure, gas-barrier properties and overall migration of poly(lactic acid) films coated with hydrogenated amorphous carbon layers. Carbon 63:274-282.

102. Maio L D, Scarfato P, Milana M R, Feliciani R, Denaro M, Padula G, Incarnato L (2013) Bionanocomposite Polylactic Acid/Organoclay Films: Functional Properties 
and Measurement of Total and Lactic Acid Specific Migration. Packag Technol Sci 27(7):535-547.

103. Störmer A, Bott J, Kemmer D, Franz R (2017) Critical review of the migration potential of nanoparticles in food contact plastics. Trend Food Sci Technol 63:39-50.

104. Adhikari B, Chaudhary D S, Clerfeuille E (2010) Effect of Plasticizers on the Moisture Migration Behavior of Low-Amylose Starch Films during Drying. Drying Technol 28(4):468-480. 